\title{
Prevention of cervical cancer in HIV- seropositive women from developing countries through cervical cancer screening: a systematic review
}

\author{
Witness Mapanga ${ }^{1,5^{*}} \mathbb{D}$, Brendan Girdler-Brown ${ }^{1}$, Shingairai A. Feresu², Tsungai Chipato ${ }^{3}$ and Elvira Singh ${ }^{1,4}$
}

\begin{abstract}
Background: There is scanty or inconclusive evidence on which cervical cancer screening tool is effective and suitable for human immunodeficiency virus (HIV)-seropositive women. The aim of this review was to assess, synthesise and document published evidence relating to the available cervical cancer screening modalities for HIVseropositive women in developing countries. This paper did not review the issue of human papillomavirus (HPV) prophylactic vaccine on HIV-seropositive women.
\end{abstract}

Methods: Five electronic databases were systematically searched from inception to January 2018 for relevant published original research examining cervical cancer prevention modalities for HPV infection, abnormal cytology and direct visualisation of the cervix amongst HIV-seropositive women in developing countries. Extra studies were identified through reference list and citation tracking.

Results: Due to methodological and clinical heterogeneity, a narrative synthesis was presented. Of the 2559 articles, 149 underwent full-text screening and 25 were included in the review. Included studies were of moderate quality, and no exclusions were made based on quality or bias. There is no standard cervical cancer screening test or programme for HIV-seropositive women and countries screening according to available resources and expertise. The screening methods used for HIV-seropositive women are the same for HIV-negative women, with varying clinical performance and accuracy. The main cervical cancer screening methods described for HIV-seropositive women are HPV deoxyribonucleic acid/messenger RNA (DNA/mRNA) testing $(n=16,64.0 \%)$, visual inspection with acetic acid (VIA) $(n=13,52.0 \%)$ and Pap smear ( $n=11,44.0 \%)$. HPV testing has a better accuracy/efficiency than other methods with a sensitivity of $80.0-97.0 \%$ and specificity of $51.0-78.0 \%$. Sequential screening using VIA or visual inspection with Lugol's iodine (VILI) and HPV testing has shown better clinical performance in screening HIV-seropositive women.

Conclusion: Although cervical cancer screening exists in almost all developing countries, what is missing is both opportunistic and systematic organised population-based screenings. Cervical cancer screening programmes need to be integrated into already existing HIV services to enable early detection and treatment. There is a need to offer opportunistic and coordinated screening programmes that are provider-initiated to promote early identification of cervical precancerous lesions.

Systematic review registration: PROSPERO CRD42018095702

Keywords: Cervical cancer, Prevention, HPV, HIV, Developing countries

\footnotetext{
* Correspondence: witnessmapanga@yahoo.co.uk

${ }^{1}$ School of Health Systems and Public Health, Epidemiology \& Biostatistics,

University of Pretoria, 5-10 H.W. Snyman Building, Pretoria, South Africa

${ }^{5}$ Harare, Zimbabwe

Full list of author information is available at the end of the article
}

(c) The Author(s). 2018 Open Access This article is distributed under the terms of the Creative Commons Attribution 4.0 International License (http://creativecommons.org/licenses/by/4.0/), which permits unrestricted use, distribution, and reproduction in any medium, provided you give appropriate credit to the original author(s) and the source, provide a link to the Creative Commons license, and indicate if changes were made. The Creative Commons Public Domain Dedication waiver (http://creativecommons.org/publicdomain/zero/1.0/) applies to the data made available in this article, unless otherwise stated. 


\section{Introduction}

With the increase in cervical cancer morbidity and mortality in developing countries, concern has shifted to how much can be done to prevent this public health challenge especially in those who are immunocompromised. With the advent of HIV in most of these developing countries especially those in sub-Saharan Africa, the burden, incidence and mortality due to cervical cancer are increasing [1-4]. HIV/AIDS in most developing countries has resulted in high cervical cancer incidence, and because of this, cervical cancer has been classified as an AIDS-defining disease [2-4]. HIV-seropositive women have been found to be at higher risk of HPV infection due to their immune-compromised status and that they are 2 to 12 times more likely to develop cervical precancerous lesions that lead to cervical cancer than HIV-negative women [2,3]. Globally, 1 to $2 \%$ of HIV-negative women develop CIN stages 2 and 3 annually whilst HIV-positive women are at $10 \%$ more prone to developing CIN stages 2 and 3 [5]. In addition, HIV is itself associated with other multiple enabling factors for cervical cancer such as lower economic status, multiple sexual partners, early sexual debut and smoking [6], and this makes prevention of cervical cancer in HIV very important.

Cervical cancer prevention is important in reducing morbidity and mortality, and there are a number of screening methods available. The screening methods include cytological-based tests (Pap smear/glass slide cytology and liquid-based cytology), HPV DNA testing and visual inspection tests (with acetic acid (VIA) and with Lugol's iodine (VILI)) [7-9]. Pap smear has been used widely in developed countries for many years with success $[10,11]$. In developing countries, the lack of proper infrastructure and qualified personnel to carry out the procedure and interpret the results has hampered the utilisation of Pap smear $[12,13]$.

However, regardless of the available screening methods and considerable evidence in reducing the burden of cervical cancer, epidemiological and health system challenges and constraints still exist in most developing countries that make it difficult for some cervical cancer screening strategies and initiatives to be available. In addition, there is a lack of both opportunistic and organised systematic population-based screenings amongst HIV-seropositive women due to fewer resources, resulting in uncoordinated screening with any available screening method. With the introduction of mass HPV vaccination for young girls in some developing countries, opportunities to offer the vaccine to HIV-positive middle-aged women through HIV health programmes exist. The safety and immunogenicity of HPV vaccine are almost comparable in HIV-positive and HIV-negative women $[14,15]$. Offering HPV vaccination, as primary cervical cancer prevention to HIV-positive women, will reduce cervical cancer incidence and morbidity.

Despite a number of evidence-based guidelines, strategies and research on cervical cancer screening or prevention in low-resource settings, slow progress in the implementation of these guidelines due to the lack of implementation experts has become a public health challenge that requires urgent solutions to mitigate the morbidity and mortality due to cervical cancer. There is little rigorous synthesised evidence on which cervical cancer screening methods are being used for HIV-seropositive women, if these current screening methods are the same for HIV-negative women and if these screening methods are effective for HIV-seropositive women. The review aims to answer the following questions: What are the screening modalities that are used to prevent cervical cancer in HIV-seropositive women in developing countries? Are these the same screening modalities that are used for HIV-negative women? Are the screening modalities effective in HIV-seropositive women? This review will investigate, identify and synthesise the existing screening modalities being used for cervical cancer in HIV-seropositive women in developing countries. Synthesising research from developing countries can provide robust evidence of context-specific cervical cancer screening methods for HIV-seropositive women to fill the gap in evidence.

\section{Methods}

\section{Search strategy}

This systematic review was registered with PROSPERO (CRD42018095702) and was carried out guided by a protocol (PROSPERO CRD42017054678) [16] and reported according to the PRISMA guidelines (Fig. 1) [17].

Two independent reviewers (WM and TC) guided by a protocol [14] searched PubMed (via the PubMed/ MEDLINE interface using the "PICO" option), CINAHL (via the EBSCO interface using keywords), Cochrane (via The Cochrane Library using MeSH terms and qualifiers), Embase and MEDLINE (via the OvidSP interface) using keywords and supplementary free-text terms until January 2018. The search terms (cervical cancer or cervical neoplasms or cervical carcinomas) AND (prevention or screening or Pap smear or VIA) AND (developing countries or underdeveloped countries or low-income countries) were used specifically for each database (an additional PDF file shows this in more detail [see Additional file 1]).

\section{Eligibility criteria}

Articles were eligible for inclusion based on inclusion criteria: original research that assessed or reported cervical cancer prevention methods for HIV-positive women (Pap smear, VIA, HPV DNA testing), 


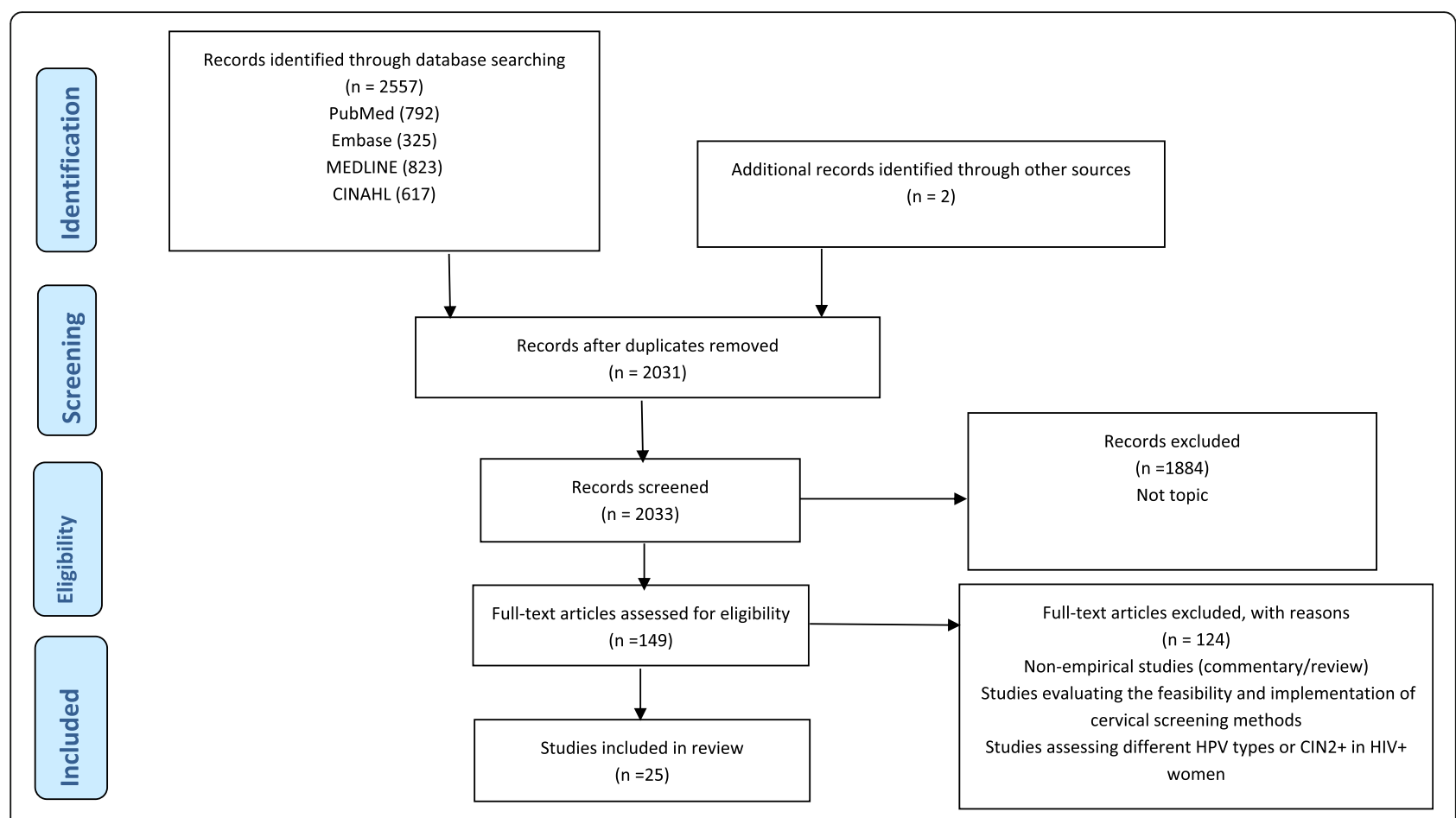

Fig. 1 Search strategy. The search strategy is reported according to the PRISMA guidelines

peer-reviewed, reported in English and done in or for regions or countries which are considered developing by the United Nations [16]. Reviews, commentaries and studies assessing cervical cancer in general were excluded from the review.

\section{Study selection}

The initial search of the databases yielded 2557 results, and additional two studies were identified through citation and reference tracking to make a combined 2559 articles. Two independent reviewers (WM and SF) conducted the screening process to identify eligible studies, and reasons for excluding studies were documented (see Fig. 1). Disagreements and other issues related to the screening process were resolved as reported in the protocol [16]. Removal of duplicates and screening of title and abstracts excluded 2212 articles. An additional 198 articles were further excluded because of not being relevant to the topic. The remaining 149 articles were reviewed in full text, and 124 studies were excluded for not meeting the eligibility criteria (an additional PDF file shows these excluded studies in more detail [see Additional file 2]). Twenty-five articles met the eligibility criteria and were included for final analysis.

\section{Data extraction}

The primary reviewer (WM) and TC double extracted the following content from the included 25 studies: title of the study, author, publication year, study design, study setting (country/region), sample size, exposures and outcomes and all results including statistics. Three additional team members, SF, BGB, and ES, assessed the extracted data to ensure accuracy, and inconsistencies were discussed and resolved through consensus. Frequency tables were used to summarise the results.

\section{Quality assessment of included studies}

The quality of the included studies was assessed using a combination of a modified version of the Newcastle-Ottawa Quality Assessment Scale and the NIH Study Quality Assessment Tools for observational cohort cross-sectional case-control and before-after studies $[18,19]$. The focus of research, key findings, study design, length of follow-up and representativeness of participants were used to ascertain quality. For an easy quality assessment process, studies were categorised into three groups namely randomised controlled trials, observational studies with control group(s) and observational studies without control group(s) [16]. Outcome measures were assessed based on whether the articles had a predefined outcome measure and if any cervical cancer prevention method was explored or its application was discussed [16]. Two independent reviewers (WM and BGB) carried out the quality assessment process, and discrepancies that arose were resolved through discussion with other team members. The average score of the two reviewers (WM and BGB) on both the quality assessment tools became the quality score for 
each study, with 0 being very low quality and 5 being high quality.

\section{Results}

Out of 2559 articles, 25 met the inclusion criteria and were synthesised for results. Table 1 summarises the study characteristics and evidence extracted from the studies respectively. Twenty-two studies (88.0\%) were conducted in and for sub-Saharan Africa, 2 (8.0\%) in Asia and 1 (4.0\%) in South America (Fig. 2). All the included studies were published within the last decade, 2008 to 2018.

All the included studies explored the clinical performance of cervical cancer screening methods/tools on HIV-seropositive women, with a few comparing them to screening HIV-negative women. There was almost a complete consistency in defining the key outcomes across the studies to indicate clinical performance, which is looking at sensitivity, specificity and positive and negative predictive values. However, the baseline characteristics of the study participants including age varied across the studies. In addition, sampling and recruitment of participants, screening process (opportunistic vs. organised), the interval on which follow-ups were conducted and the type of visits (one-visit schemes vs. return visit scheme) were also different. Completeness of data, data management methods, adjustment for confounders and analysis also differed across the studies. Therefore, because of this heterogeneity, a narrative descriptive synthesis was performed.

\section{Study design}

The included studies ranged from cross-sectional to randomised clinical trials. Classifying them according to the protocol [16], most of the included studies were observational studies without control groups $(n=20,80.0 \%)$. There were three observational studies with a control group (12.0\%) and two (8.0\%) randomised clinical trials (see Table 1).

Of the two randomised clinical trials (see Table 1), one compared the diagnostic accuracy between VIA and VILI [20], whilst the other clinical trial evaluated the efficacy and safety of the screen-and-treat using either HPV DNA test or VIA [21]. The three observational studies with a control group compared VIA to the sequential use of VIA and VILI [22], and the other two assessed the performance of careHPV ${ }^{\circledR}$ (a rapid batch diagnostic test for detection of high-risk HPV DNA vs. HPV genotyping [23, 24].

The 20 observational studies without a control group evaluated clinical performance of VIA, careHPV ${ }^{\circ}$, VILI with digital cervicography, Pap smear, HPV test, HPV DNA, cryotherapy and Cellslide ${ }^{\circ}$ automated liquid-based cytology [25-37]. The other studies evaluated the see-see and treat strategy of VIA/VILI and cryotherapy [38], Hybrid Capture-2 ${ }^{\circ}$ (HC2), INNO-LiPA ${ }^{\circ}$, p16INK4a ELISA $^{\circ}$, Xpert $\mathrm{HPV}^{\circ}$, high-risk $\mathrm{HPV}$ messenger RNA and $\mathrm{OncoE}^{\circ}$ for HPV detection [39-44].

\section{Cervical cancer screening methods/tools for HIV- seropositive women}

Most of the studies were conducted in sub-Saharan Africa, and they evaluated and compared the performance of VIA, detecting high-risk HPV DNA using careHPV ${ }^{\circ}$, INNO-LiPA ${ }^{\circ}, \mathrm{HC}^{\circ}$, Xpert HPV or OncoE6 ${ }^{\circ}$; a combination of VIA/VILI with digital cervicography; Pap smear; colposcopy and test and treat using VIA/VILI; or HPV DNA and cryotherapy [20-29, 32-44]. The two studies conducted in Asia evaluated VIA, VILI, cytology, HPV testing and colposcopy to find an accurate, feasible and affordable cervical screening method for HIV-infected women [30, 34]. In Cambodia, they compared VIA and Pap smear, looking at the correlation between the two amongst HIV-infected women [31].

\section{Primary prevention methods}

The p16INK4a ELISA ${ }^{\circ}$, a surrogate marker for high-risk HPV, was assessed as a potential primary cervical cancer screening tool for HIV-seropositive women in Kenya [41].

\section{Secondary prevention methods}

For secondary prevention, VIA was the most frequently used and evaluated screening method for HIV-seropositive women in 16 of the 25 articles included $(n=16,64.0 \%)$. Comparison between Pap smear and VIA to assess which is the better screening method was explored in 4 of the included articles $(n=4,16.0 \%)$. Evaluation of Pap smear, VIA, HPV test and colposcopy was also examined in 4 of the studies $(n=4,16.0 \%)$, whilst VIA and VILI were assessed in only 1 study $(n=1,4.0 \%)$. HPV DNA/mRNA testing with various methods and tools such as $\mathrm{HC}^{\circ}$, INNO_LiPA ${ }^{\oplus}$, HPV genotyping, careHPV ${ }^{\circ}$, hrHPV mRNA, Xpert $\mathrm{HPV}^{\circ}$ and OncoE6 $6^{\circ}$ was evaluated in 9 studies $(n=$ 9, 36.0\%). In the test/screen and treat initiatives, HPV DNA and cryotherapy, VIA and cryotherapy, and VIA/ VILI and cryotherapy were evaluated in two of the studies $(n=2,8.0 \%)$.

\section{Efficacy and accuracy of cervical cancer screening methods in HIV-positive women VIA}

A number of studies [21, 22, 25, 27-30, 32, 34, 35, 43] have all reported VIA performance in detecting cervical intraepithelial neoplasia grade $2+(\mathrm{CIN} 2+)$ that is generally consistent, with sensitivity of $55.0-80.0 \%$ and specificity of $65.0-83.0 \%$ (see Table 2). However, some evidence [25, 32] reported specificity of $47.3 \%$ and $51.0 \%$, which are lower than what was found in other 


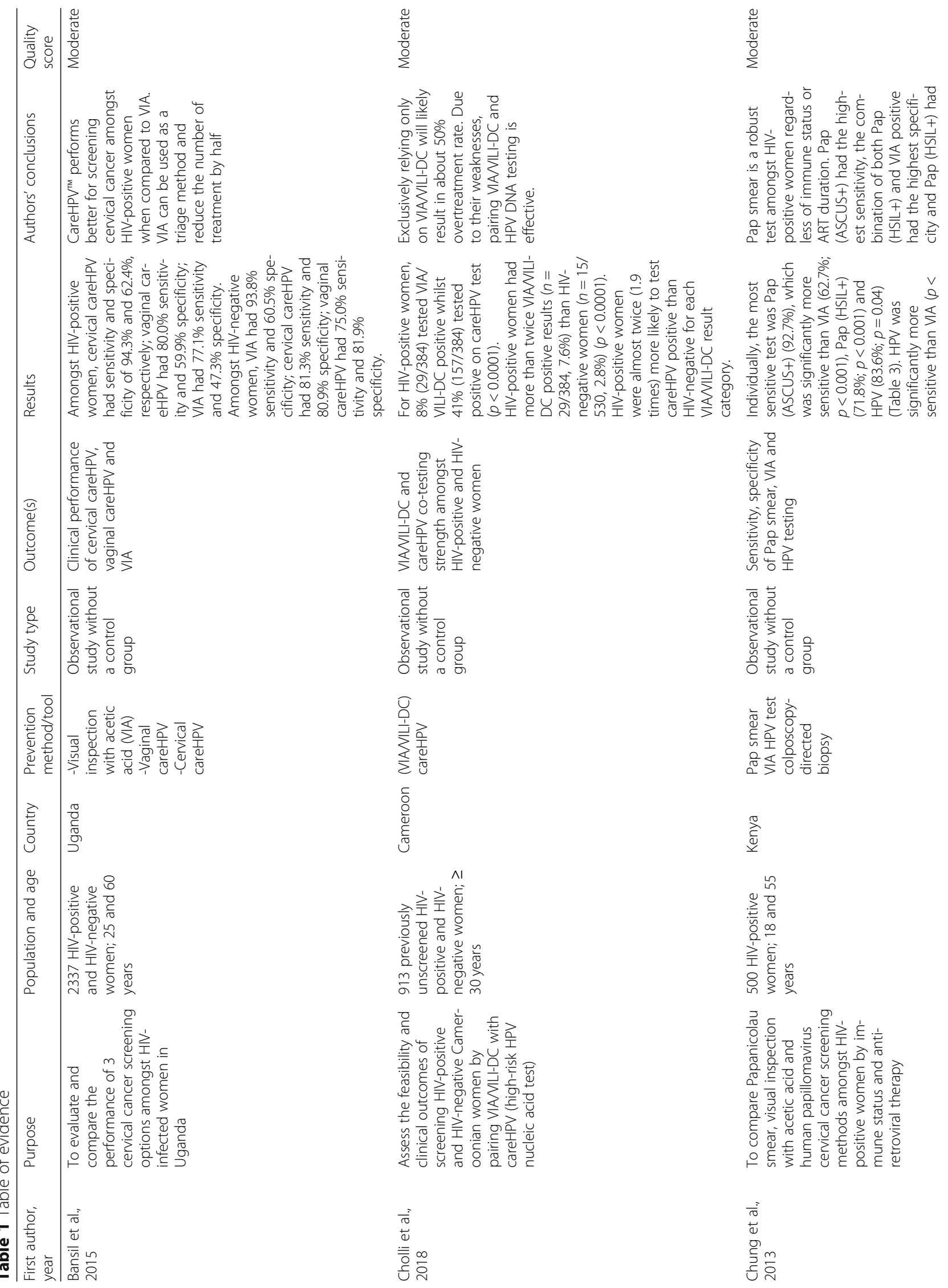




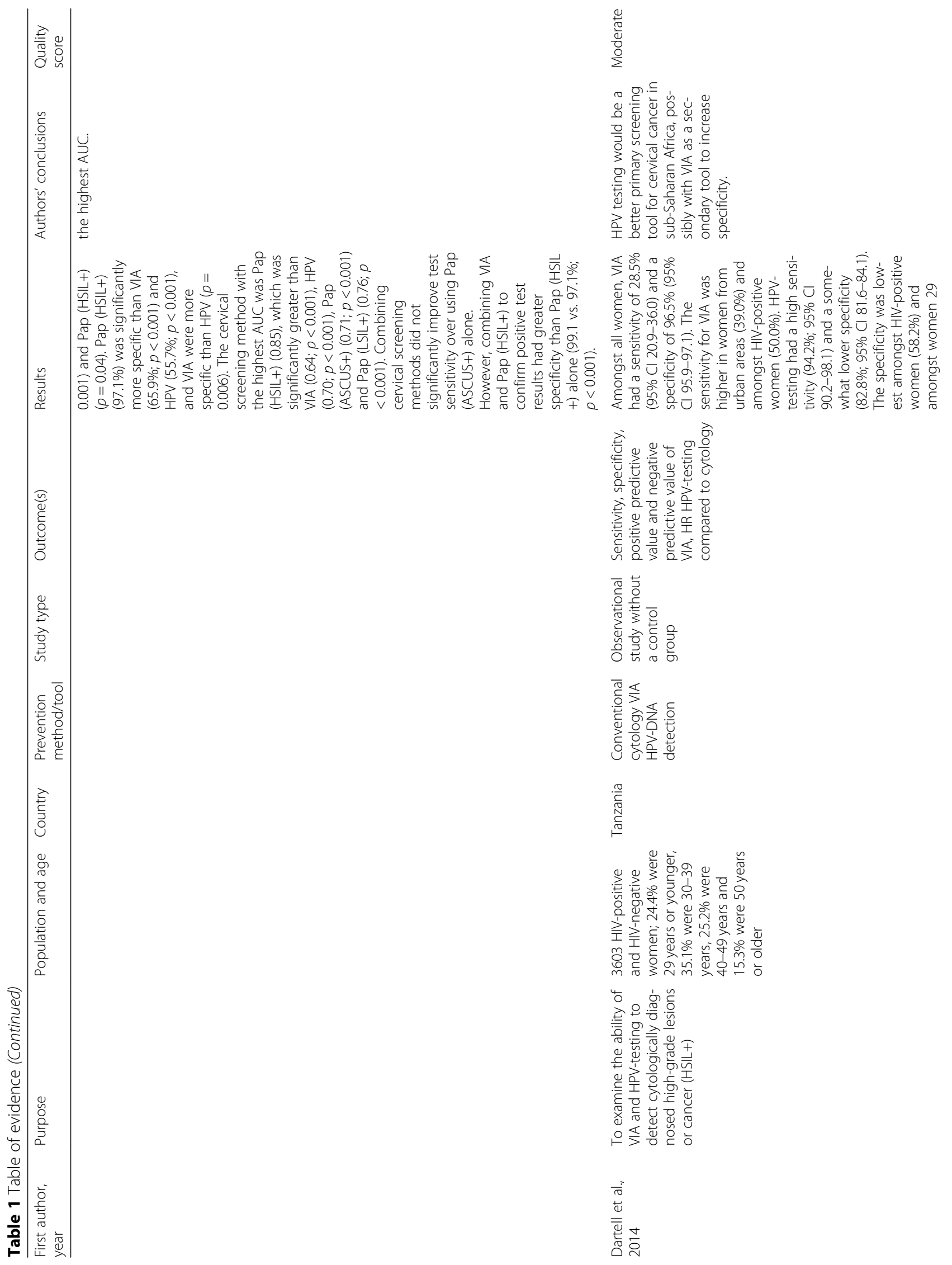




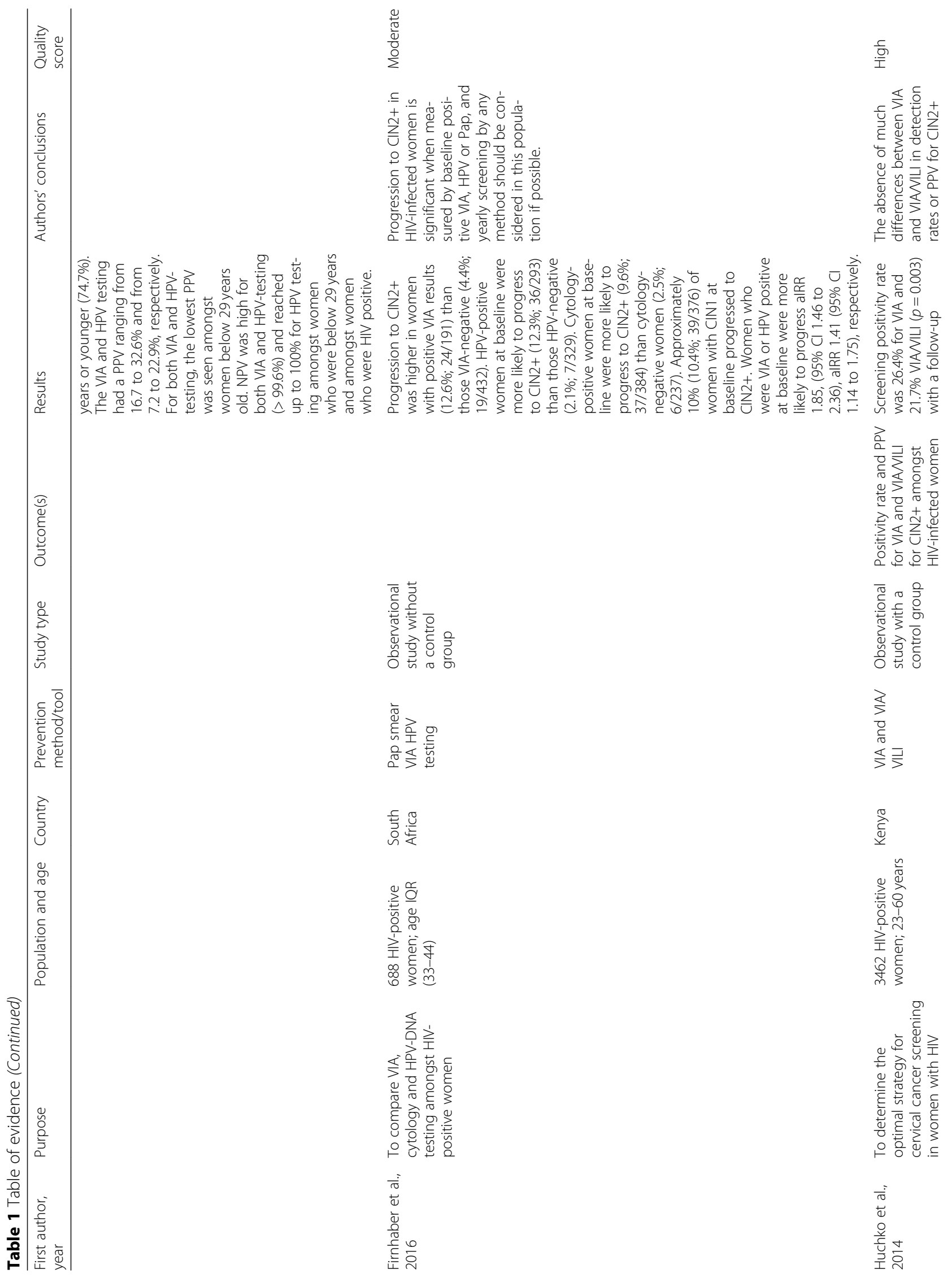




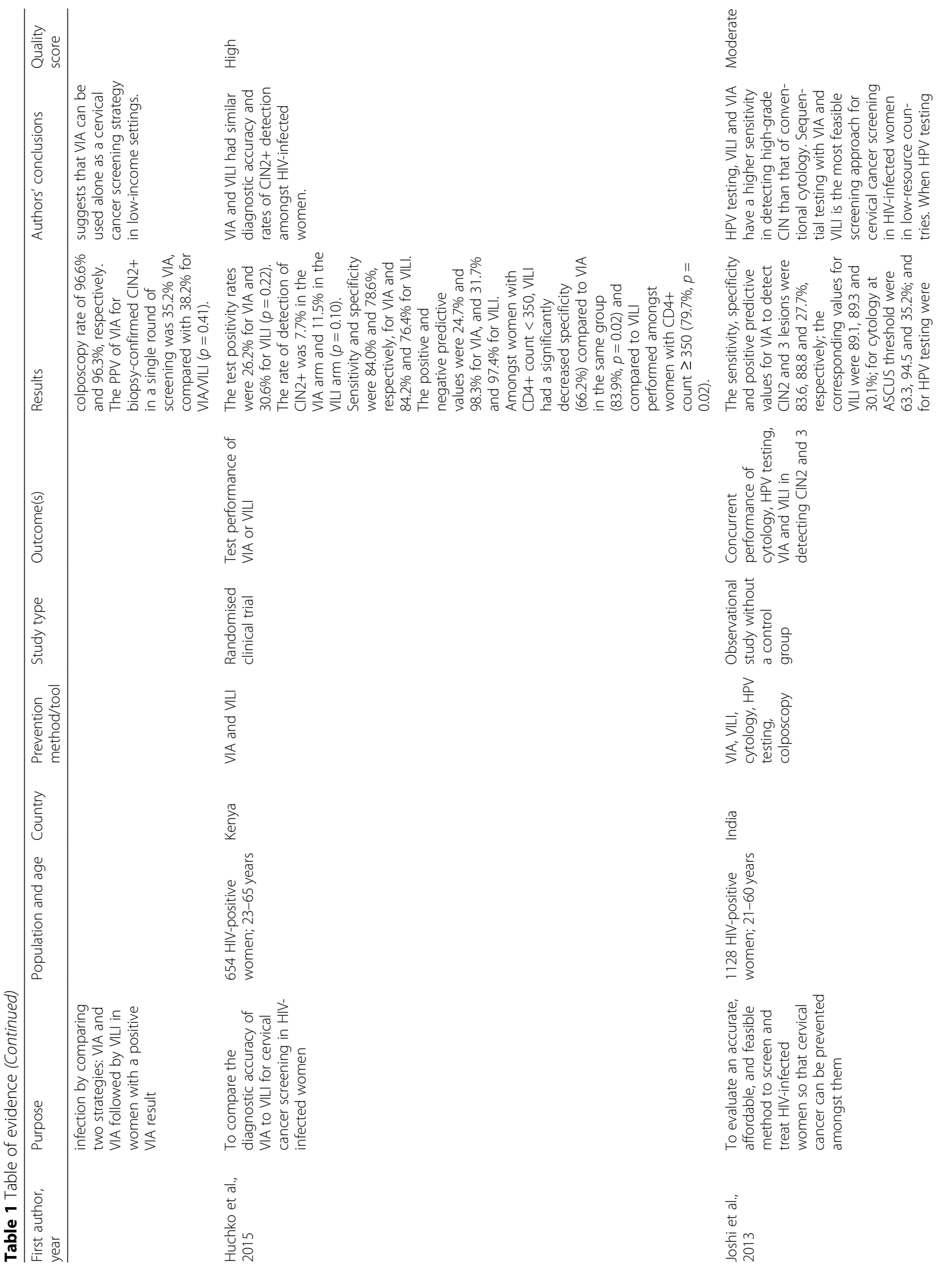




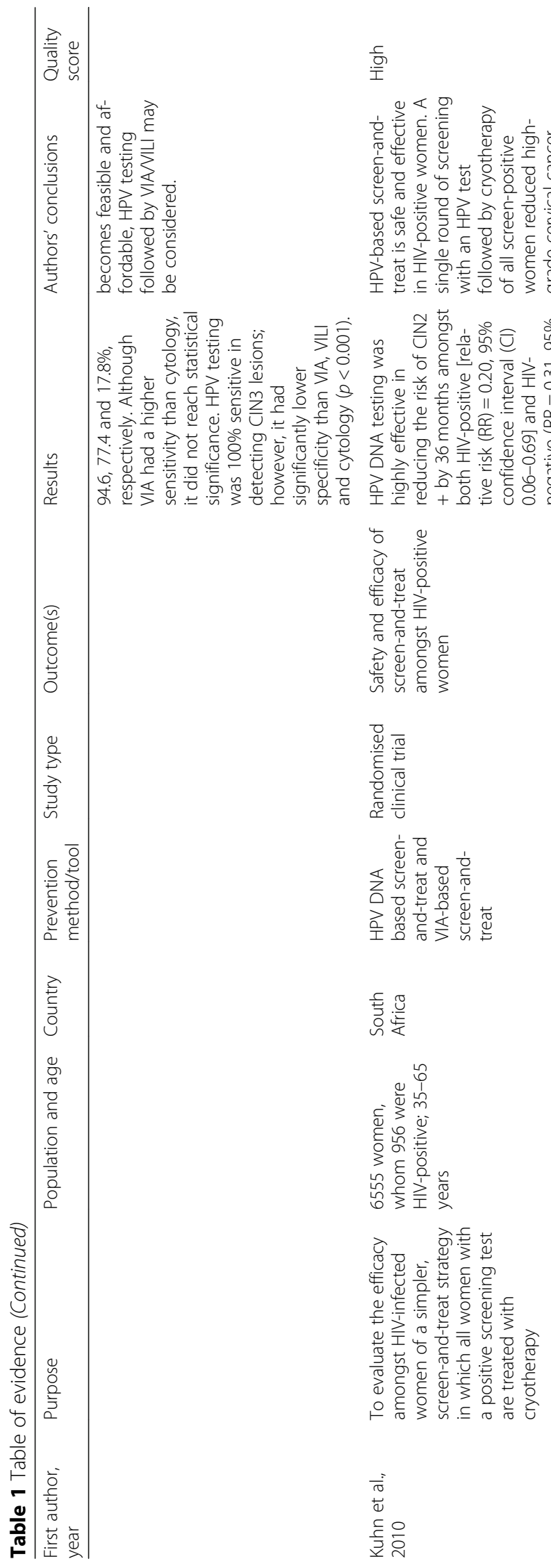




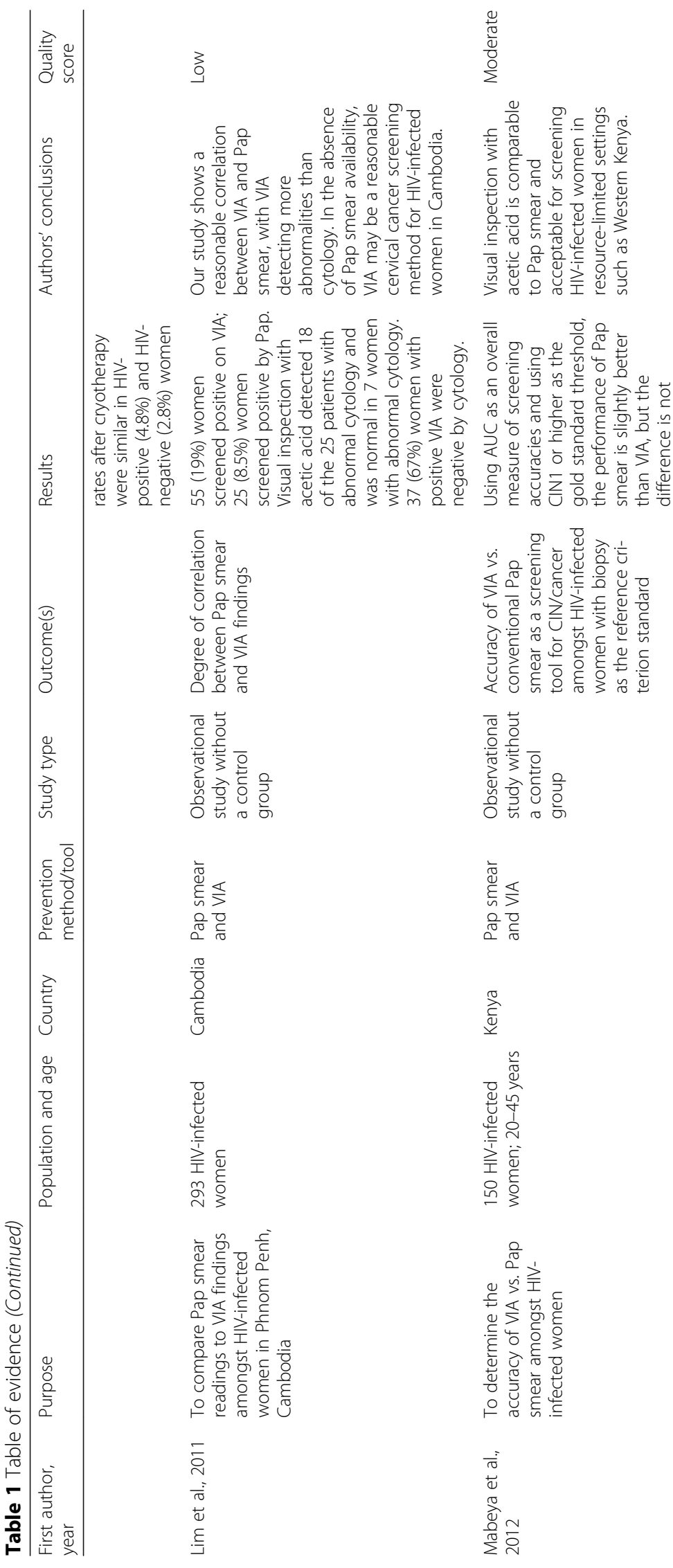




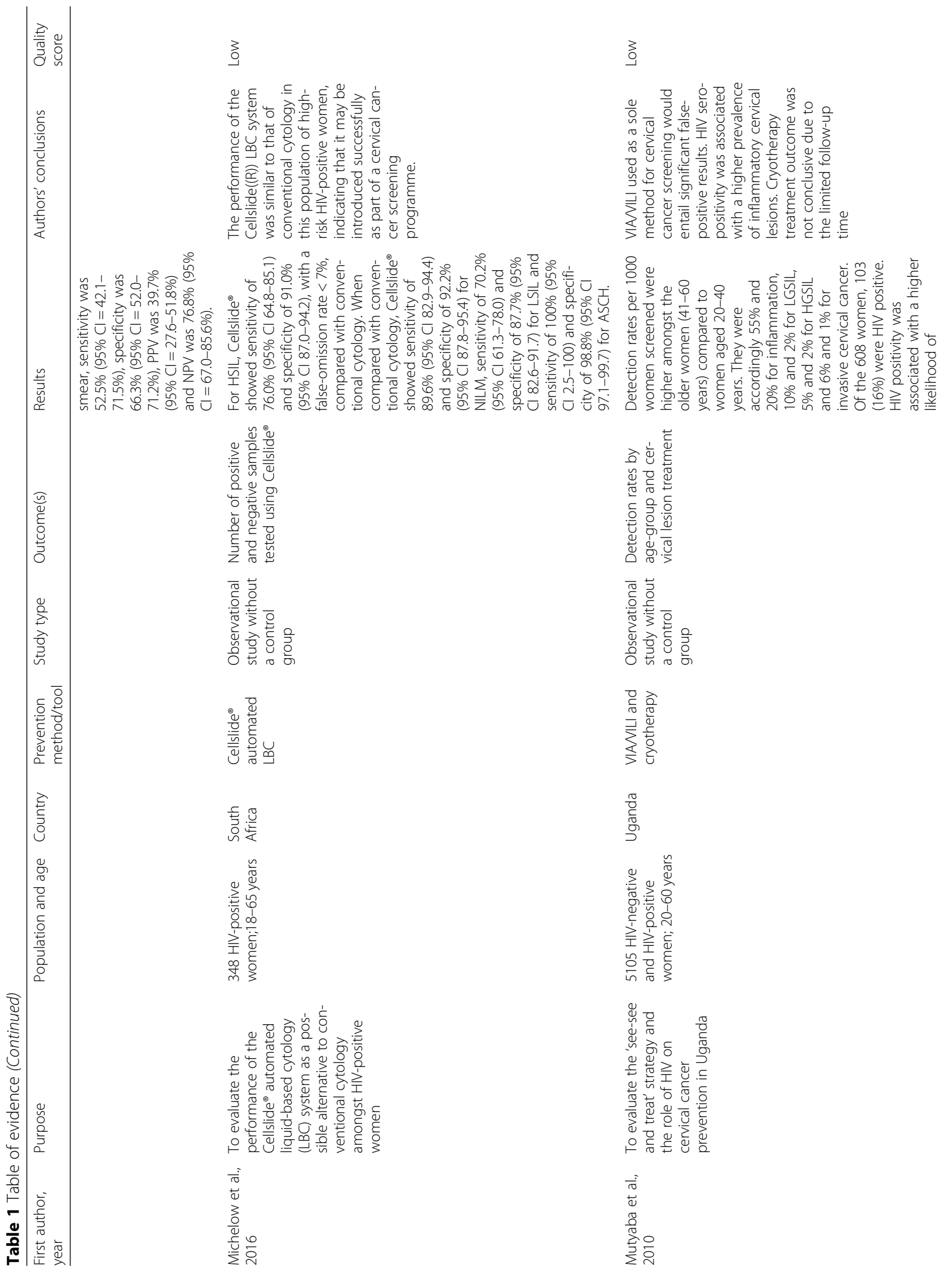




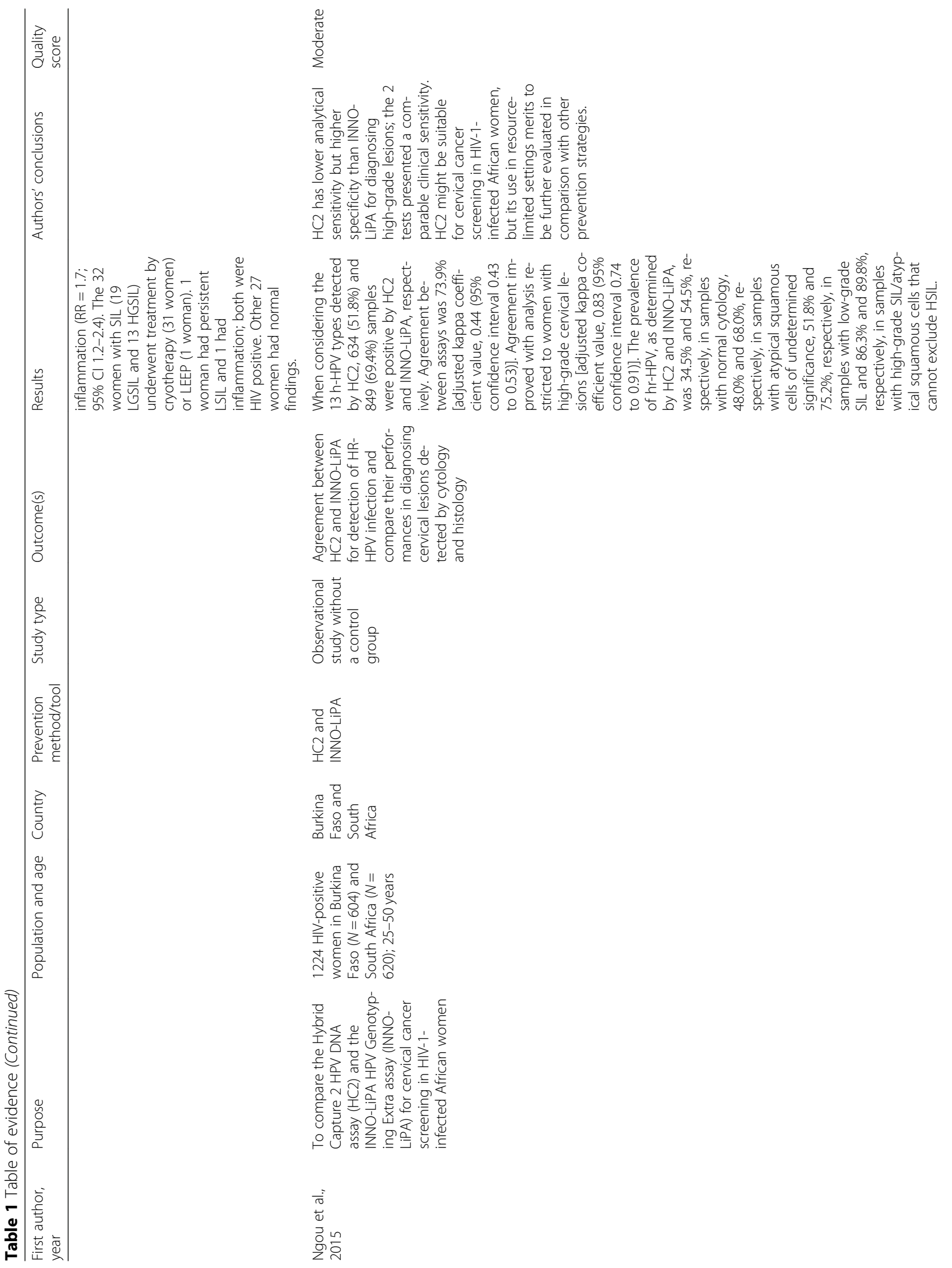




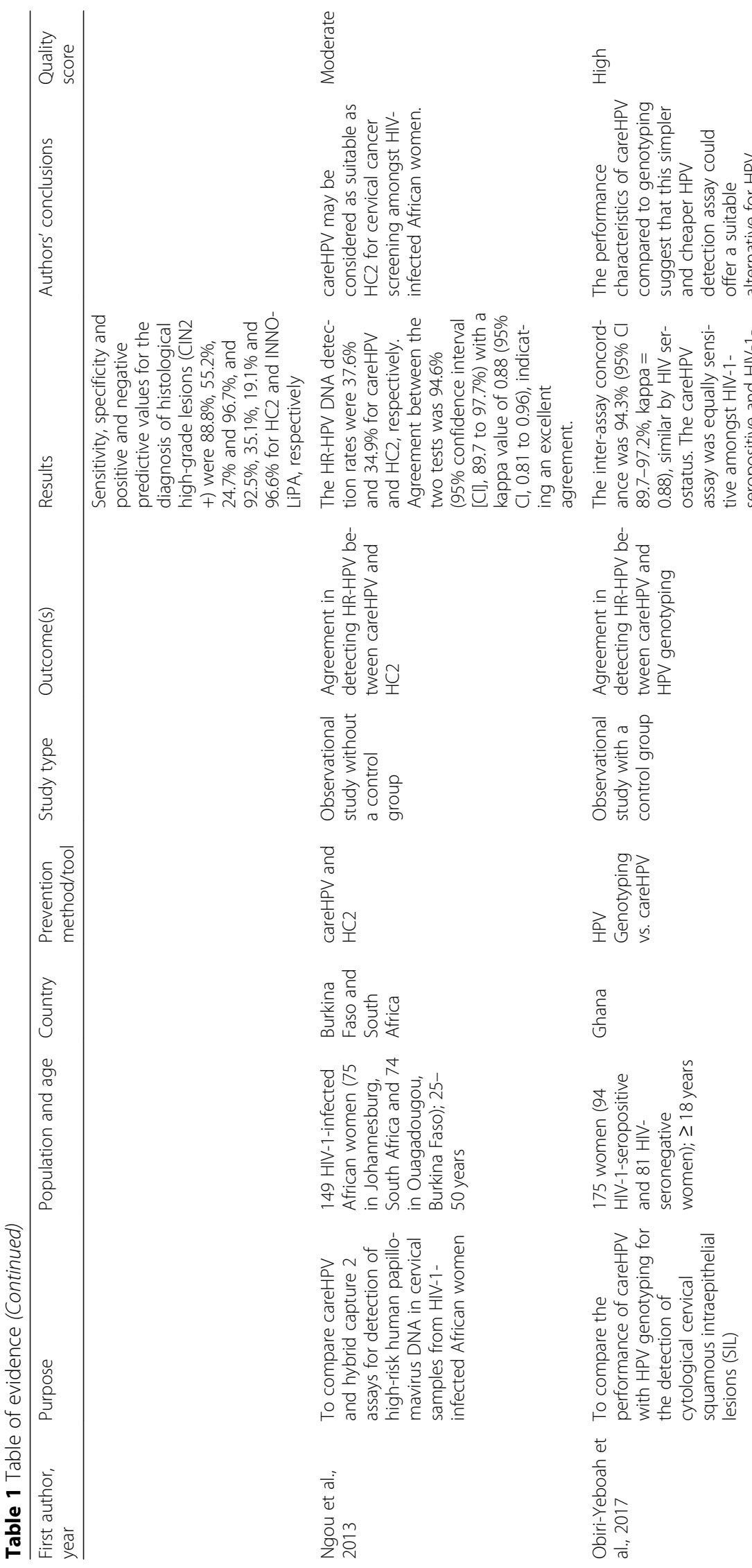




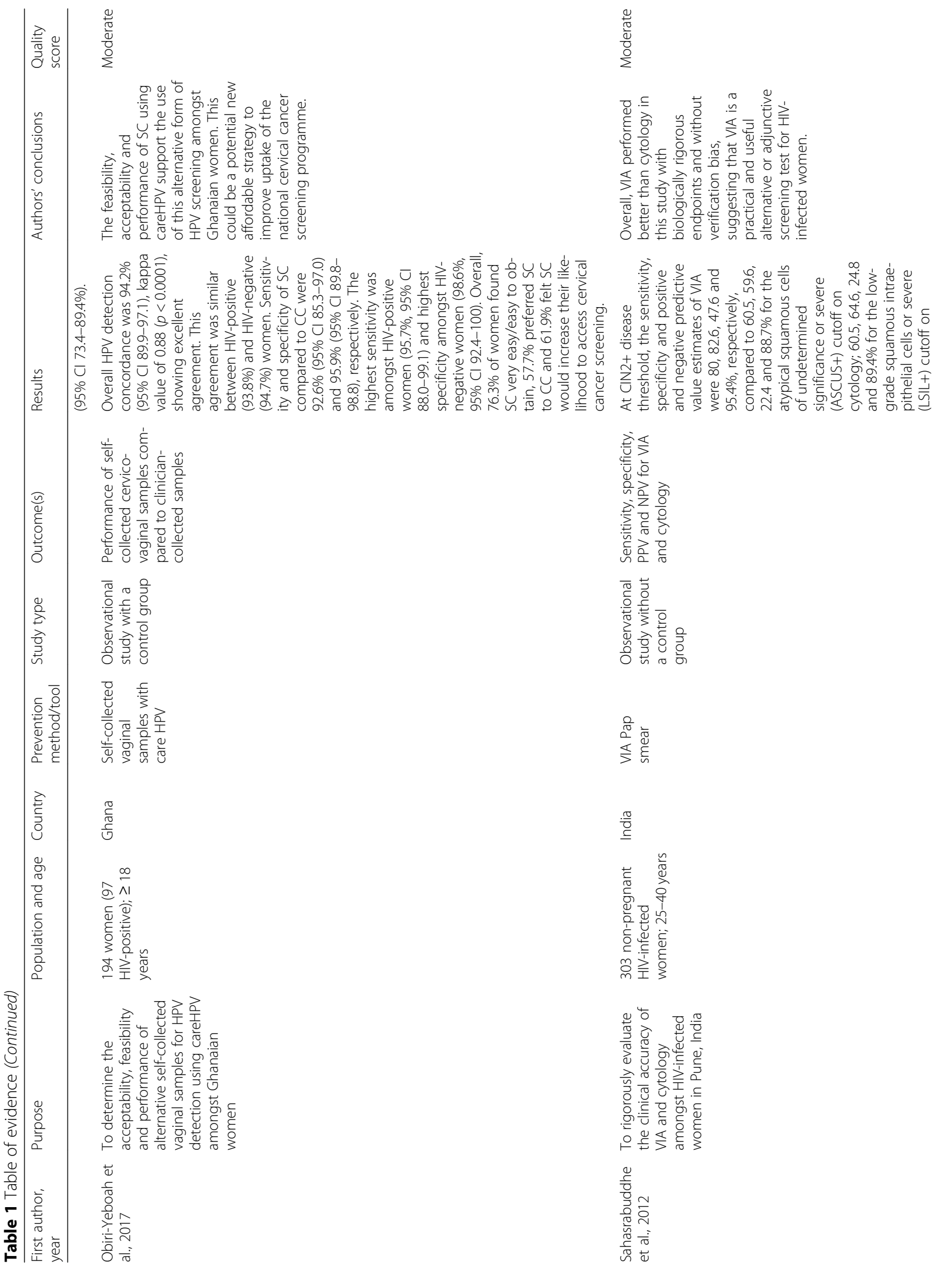




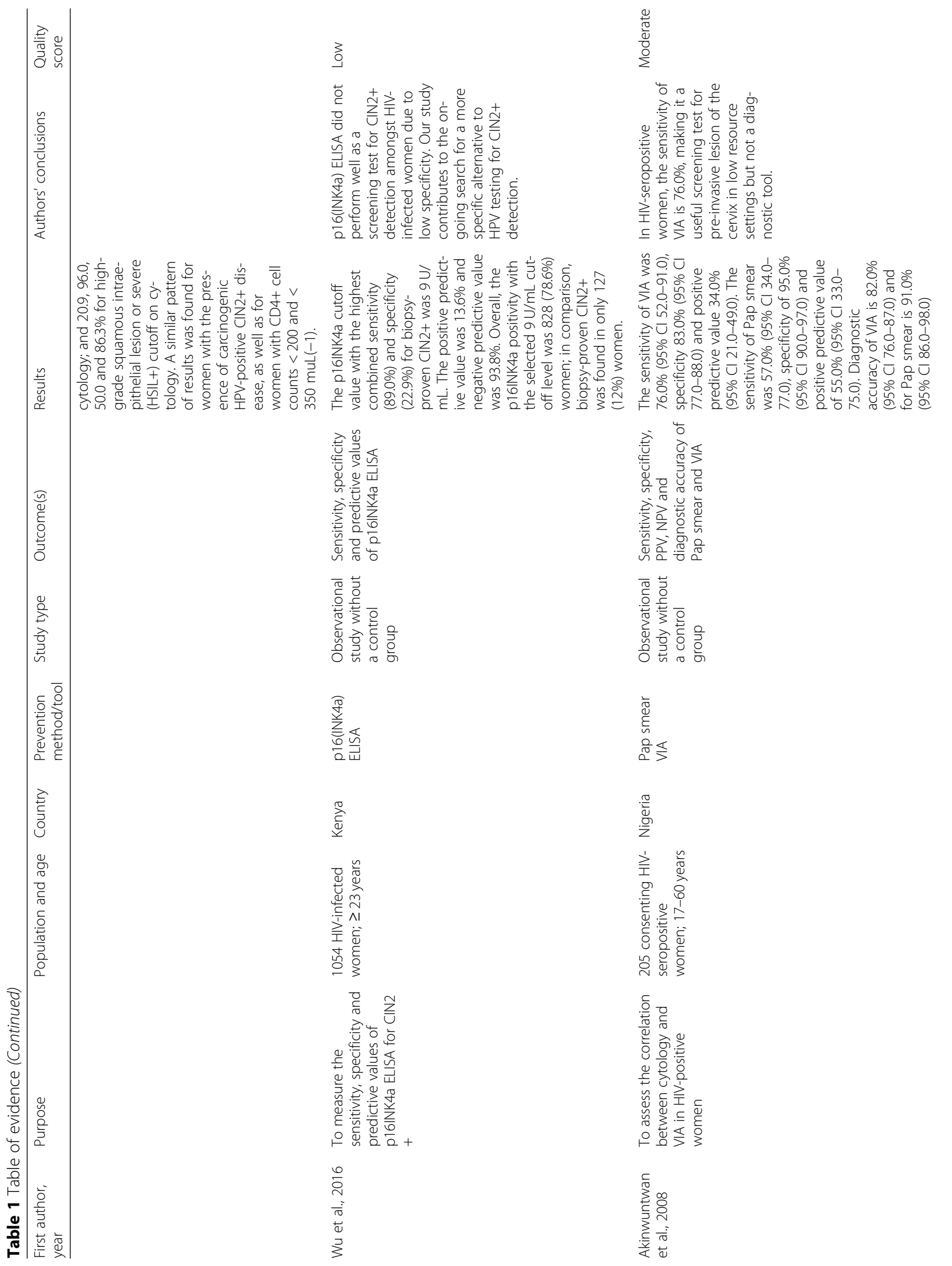




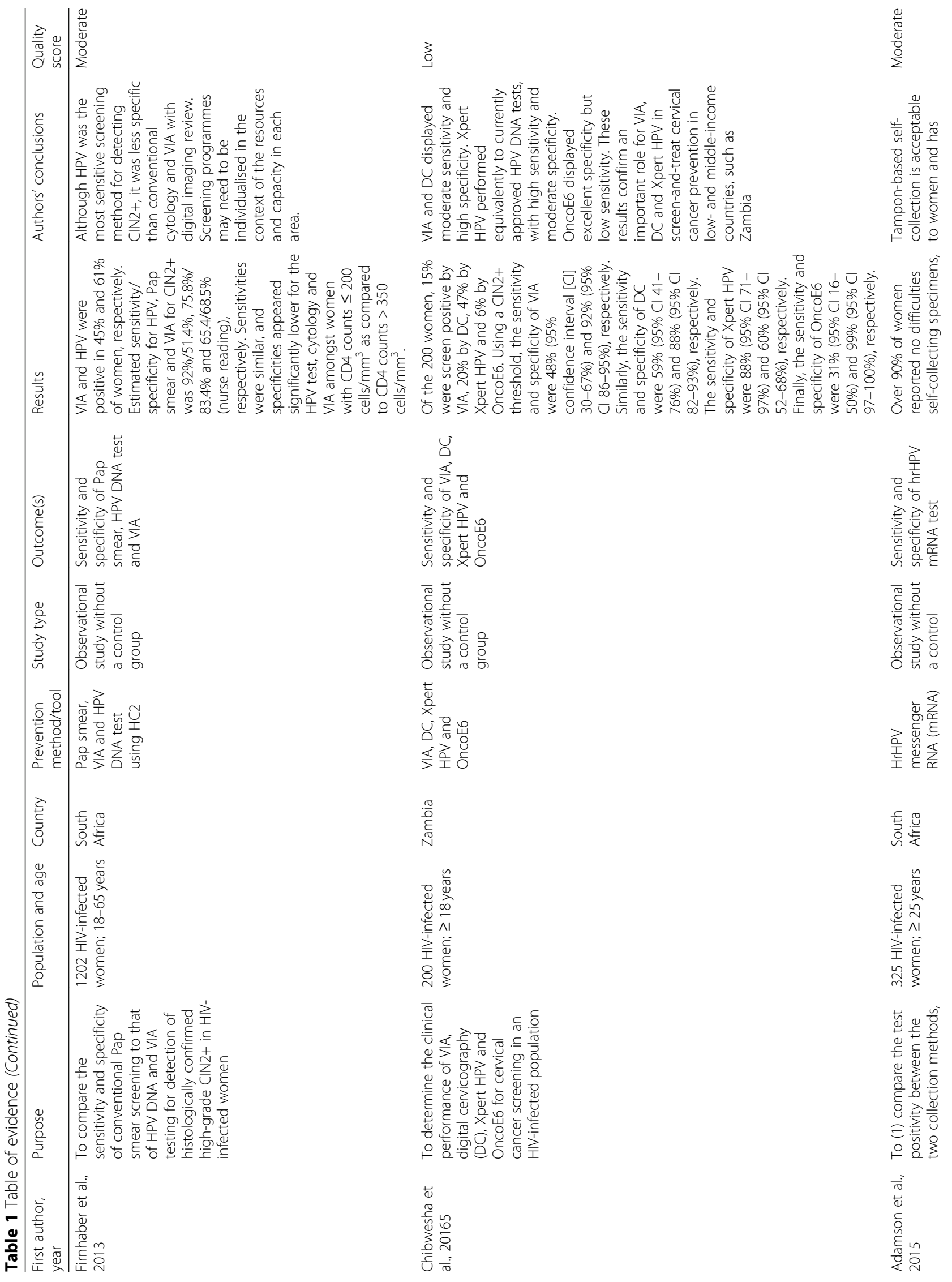




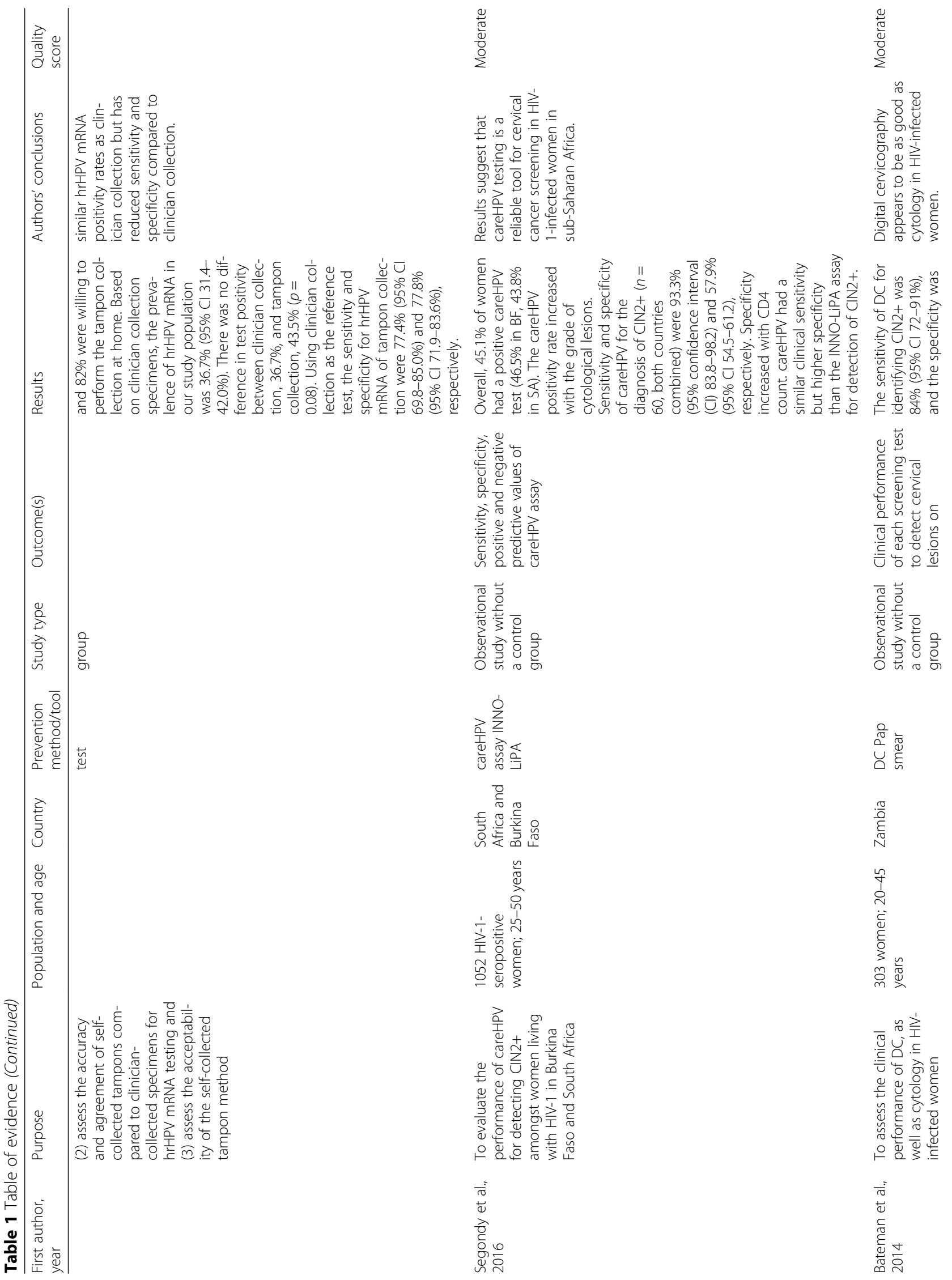




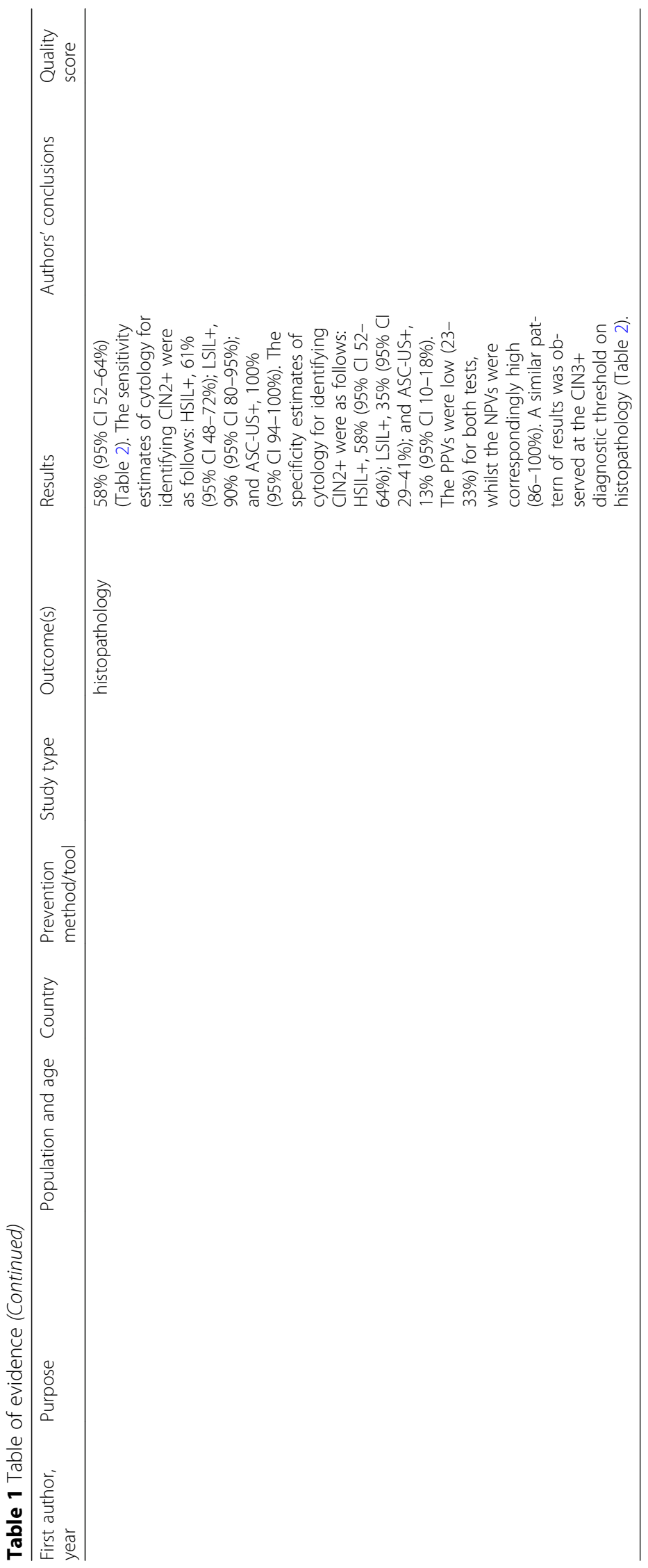




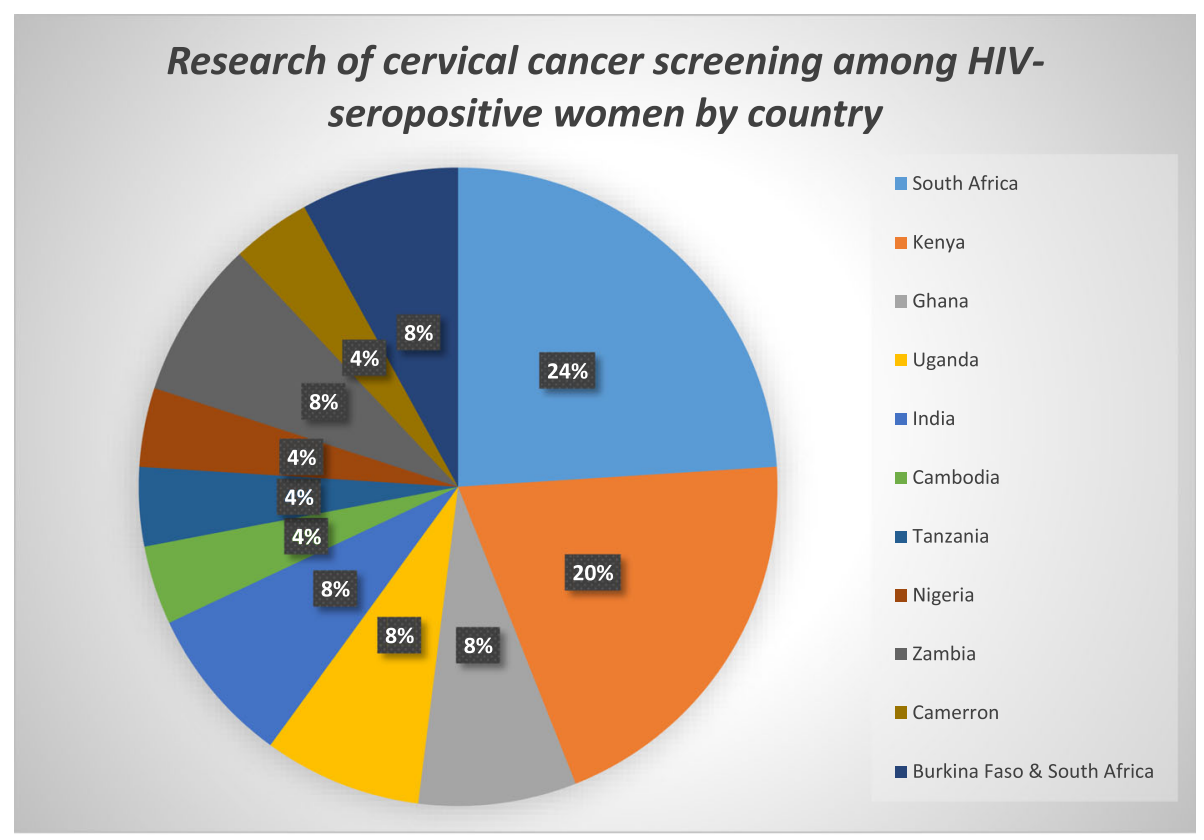

Fig. 2 Research of cervical cancer screening amongst HIV-seropositive women by country

studies; whilst in Zambia [43], there was a reported specificity of $92.0 \%$, which was higher than in other areas. As a diagnostic test, VIA had positive and negative predictive values of $38.6 \%$ ( $95 \% \mathrm{CI}=28.8-49.3 \%$ ) and $79.1 \%$ (95\% CI $=67.8-87.2 \%)$, respectively [32], and this was comparable to the reported positive predictive value of $35.2 \%$ [22].

\section{VILI}

Using the CIN2+ threshold (see Table 2), VILI has a better sensitivity and specificity when compared to VIA, with sensitivity ranging from 68.0 to $96 \%$ and specificity of 71.0 to $91.0 \%$ [22, 29].

\section{Digital cervicography}

Two studies in Zambia reported different efficacy of digital cervicography (DC) in screening for CIN2+ amongst HIV-positive women. The first study [43] reported a sensitivity of $59.0 \%$ (95\% CI 41.0-76.0), specificity of $88.0 \%$ (82.0-93.0), positive predictive value (PPV) of $49.0 \%(32.0-65.0)$ and negative predictive value (NPV) of 92.0\% (95\% CI 87.0-96.0), whilst the second study [37] indicated that DC had high sensitivity of $84.0 \%$ (95\% CI 72.0-91.0) but low specificity of $58.0 \%$ (95\% CI 52.0-64.0), PPV of 33.0\% (95\% CI 26.0-41.0) and NPV of 93.0\% (95\% CI 88.0-96.0).

\section{Cytology-based tests}

Sensitivity and specificity of Pap smear in detecting CIN2+ in HIV-seropositive women have been shown to be between 45.0 and $76.0 \%$ and 58.0 and $98.0 \%$, respectively [27, 30, 32, 34, 35, 37]. This clinical performance of Pap smear was similar to Cellslide ${ }^{\circ}$ automated liquid-based cytology which recorded a sensitivity of $76.0 \%$ (95\% CI $64.8-85.1)$ and a specificity of $91.0 \%$ (95\% CI 87.0-94.2) [33].

\section{Tests/tools for high-risk HPV DNA detection}

The sensitivity of high-risk human papillomavirus (HR-HPV) DNA detection tests/tools such as careHPV ${ }^{\circ}$, $\mathrm{HC}^{\circ}$ test, INNO-LiPA ${ }^{\circ}$, Xpert $\mathrm{HPV}^{\circ}$ and P16INK4a ${ }^{\circ}$ is better when compared to cytology-based tests and visual tests as indicated by a sensitivity of $80.0-97 \%$. However, the specificity of these HPV tests is similar in some cases but mostly lower to cytology or visual tests, $51.0-78.0 \%$ $[21,23-25,27-30,40,42,43]$. Although the OncoE6 ${ }^{\circ}$ had a specificity of $99.0 \%$ (95\% CI $97.0-100)$, it had a low sensitivity of between 16.0 and $50.0 \%$ [43].

\section{Clinical performance of combined screening methods/ tests VIA and Pap smear and VILI and Pap smear}

Sequential testing of HIV-seropositive women with VIA and Pap smear did not result in any significant changes in sensitivity which was $50.0-72.0 \%$, but there was a significant change in specificity (97.0-99.5\%) when compared to individual VIA or Pap smear screening [27, 30]. The clinical performance of testing with both VILI and Pap smear was almost similar to using VIA and Pap smear, with sensitivity being 55.1\% (95\% CI 40.2-69.3\%) and a slightly increased specificity of $99.6 \%$ (95\% CI 99.0-99.9\%). 


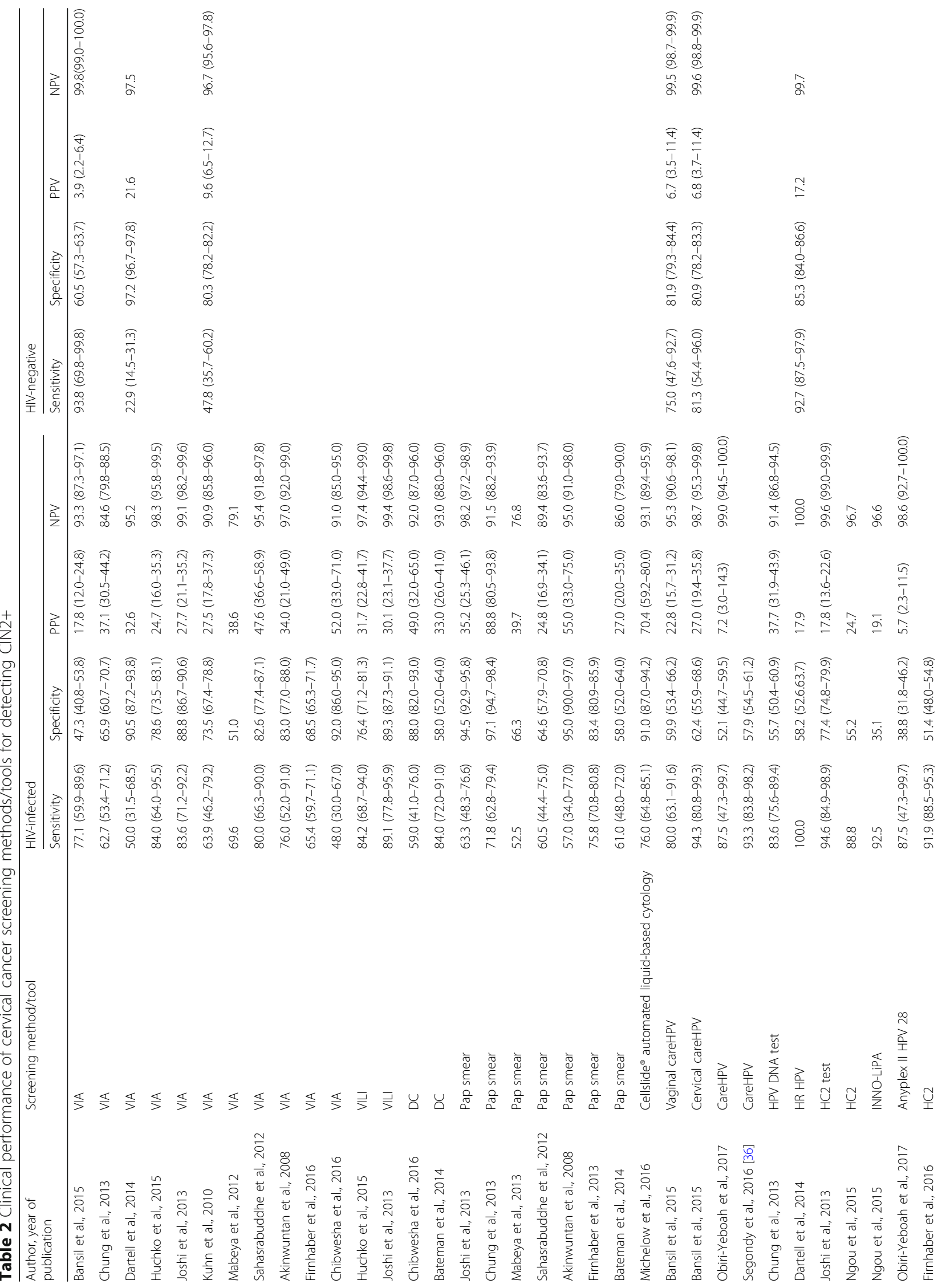


Mapanga et al. Systematic Reviews

(2018) 7:198

Page 21 of 27

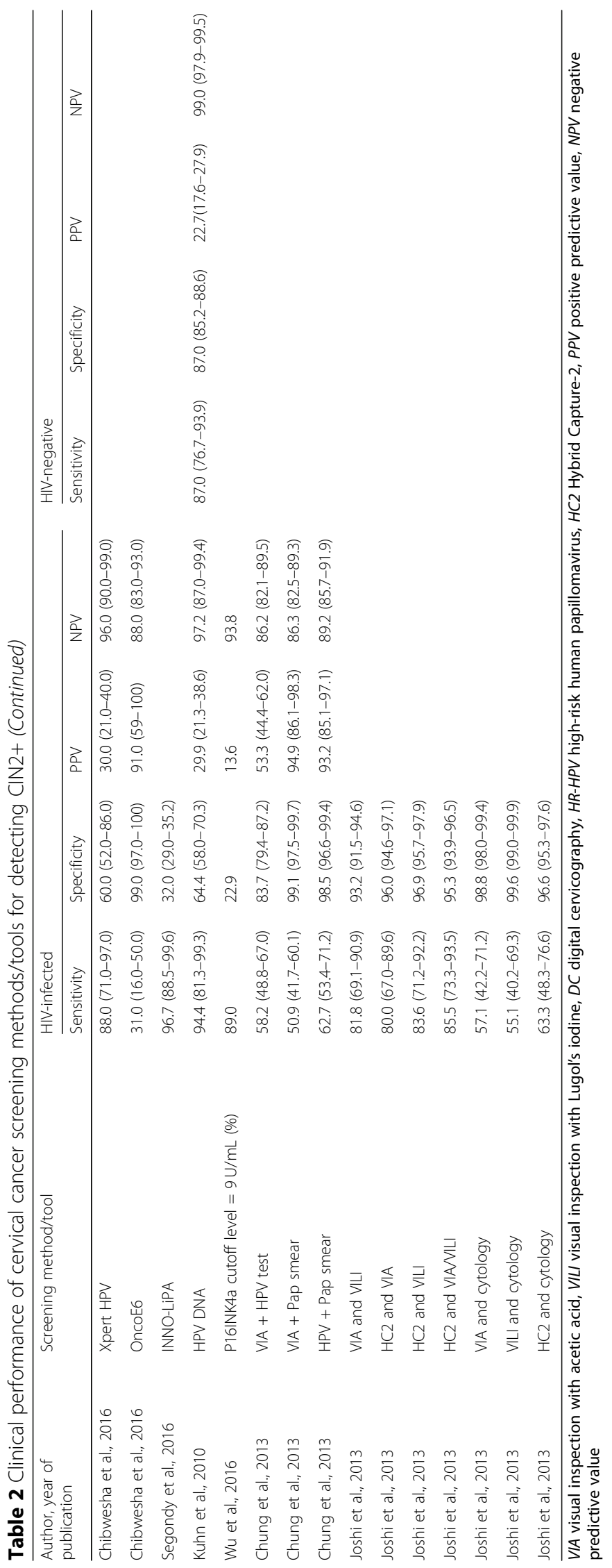




\section{VIA and HPV testing and VIA/VILI and $\mathrm{HC2}^{\circ}$}

Some findings indicated that a combination of VIA and testing for HPV did not improve sensitivity or specificity when compared to the use of individual tests, with sensitivity of clinical performance of the combination being $58.2 \%$ (95\% CI $48.8-67.0 \%$ ) and specificity of $83.7 \%$ (95\% CI 79.4-87.2\%) [27]. However, in India, it was reported that the use of either VIA or VILI and HPV testing using $\mathrm{HC}^{\circ}$ showed slightly better performance with a sensitivity of $85.5 \%$ (95\% CI $73.3-93.5 \%)$ and specificity of 95.3\% (93.9-96.5\%) [30].

\section{VIA and VILI}

The use of a combination of VIA and VILI in detecting CIN2+ in HIV-seropositive women resulted in an increased clinical performance with a sensitivity of $81.8 \%$ (95\% CI $69.1-90.9 \%)$ and specificity of $93.2 \%$ (95\% CI 91.5-94.6\%) [30]. These results indicate that a combined use of both VIA and VILI can counter false-positive results that are prone when both are used as sole methods [38].

\section{Screen-and-treat method}

In a follow-up of 36 months, screen-and-treat using HPV DNA testing and cryotherapy significantly reduced CIN2+ in HIV-positive women, with a relative risk of 0.20 (95\% CI 0.06-0.69). Screen-and-treat using HPV DNA testing and cryotherapy had better positive outcomes when compared to screen-and-treat using VIA and cryotherapy [21]. In Uganda, the findings indicated that using VIA and cryotherapy alone has the potential of resulting in overtreatment of patients because of high false-positive rates [38]. To reduce these high false-positive complications, a see-see and treat method using VIA, colposcopy and cryotherapy was seen to be effective as it reduced overtreatment by $72 \%(439 / 625)$ [38].

\section{Quality assessment of included studies}

Overall, most of the studies $(n=16,64.0 \%)$ were determined to be of moderate quality, that is, a score of 3 'yes' out of 5 on the quality scale. Only four studies $(16.0 \%)$ were considered 'high' quality, that is, a score of 4 ' 'yes' out of 5 . Five studies (20.0\%) were considered to be of low quality and had a score of 2 'yes' or below out of 5 .

Only five studies (20.0\%) had control groups, and this made it difficult to confidently ascertain if the reported findings were due to the screening method or it was by chance. Most of the studies did not evaluate the value of the screening modalities since they did not follow up the screened individuals to fully assess their effectiveness or account for disease regression or progression. Although a few studies followed up the screened HIV-positive women, the follow-up period was not adequate to measure the effectiveness of the screening methods or offer reasons for lost to follow-up of those who were due for their second screening procedure. Some of the studies did not measure confounders or include them in their analyses, with a few mentioning confounders and their expected influence on the results.

There were limited study design and methodology description in some articles, and these made it difficult to gauge if the reported findings were from an evaluative programme instead of a rigorous research. There was no mention of how participants were randomised or if randomisation was conducted in some of the studies that had a control group, and this made it difficult to attribute the reported results to the evaluated screening methods. In studies that evaluated a number of screening methods, there is a likelihood that some might have overestimated the sensitivity and specificity of the screening methods because in their analyses, they failed to calculate a dichotomous result to cater for those with negative screening results from other methods.

\section{Discussion}

The high-risk rate that HIV-seropositive women have towards developing cervical cancer renders the lack of specific evidence on which cervical cancer screening method is suitable and effective for them, a public health challenge. This review attempts to offer evidence on which cervical cancer screening approach or method is 'better' for HIV-seropositive women in developing countries and offer policymakers and health leadership a base to formulate solid screening guidelines.

This review has shown that there is not yet a standard screening method/tool for cervical cancer screening amongst HIV-seropositive women because each method has its benefits and risks that require to be considered when using it. However, this risk-benefit scale is usually considered secondary in developing countries because the availability of a screening method, whether effective or not, is important. In addition, this review has shown that there is no better screening method that fits the healthcare system of every developing country because priorities, resources and implementation of guidelines are different. Since all the cervical cancer screening methods being used for HIV-positive women are the same for HIV-negative women, careful analysis of each method's risks and benefits is required to help decisions on which method to use in the meantime as further research is conducted to find the 'best' screening method.

Due to the challenges in establishing Pap smear as a national screening programme as has been done in developed countries, the use of VIA as the screening method of choice amongst both HIV-positive and HIV-negative women has increased significantly in 
developing countries $[14,45]$. In as much as VIA is being used more often because of its easy applicability even by nurses, evidence have shown that the use of VILI can increase the efficacy and accuracy amongst HIV-positive women [20,30]. The performance of VIA was reported to be much better in HIV-negative than HIV-positive women [25], and there are more high false-positive rates amongst HIV-positive women [34, 38]. These findings might indicate that sequential screening using both VIA and VILI may be beneficial amongst HIV-seropositive women (see proposed opportunities in Fig. 3). The sequential use of VIA and VILI has indicated a better clinical performance and risk-benefit balance when compared to their use individually [20], and this might be a combination method that developing countries can use for HIV-seropositive women. However, VILI's use in developing countries is not at the same scale as that of VIA because of the cost issues associated with iodine when compared to acetic acid. In addition, lessons learnt from Ethiopia indicated that implementation of visual-based screening methods amongst HIV-seropositive women requires provider initiation as a complimenting element [46].

As the implementation of VIA and VILI continue to grow in developing countries, the risks of misdiagnosing associated with visual inspection methods (VIA and VILI) should be carefully monitored amongst HIV-seropositive to prevent subjecting these women to unnecessary treatment as well as waste resources. This is supported by synthesised evidence from a review of the visual inspection methods [45]. Therefore, developing countries may be better off using VIA and VILI as screening tools not as diagnostic tests. In addition, the see-see-and treat combination using VIA or VILI coupled with colposcopy and treating with cryotherapy has the potential of significantly reducing false positives and preventing overtreating in clients who will not need cryotherapy [38].

Detecting of HR-HPV has been shown to be an effective secondary screening method for cervical cancer amongst HIV-seropositive, with almost all the HPV tests indicating better clinical performance when compared to cytology-based and visual-based tests [23-25, 27, 28, 30, 36, 39, 40]. With long-term persistent infection with HPV almost always associated with the development of cervical cancer [47-50], emerging evidence suggest HPV testing as a better way as compared to cytology-based or visual screening methods [51]. A sequential screening of cervical cancer using VIA or VILI and HPV testing maybe ideal in developing countries as this will reduce the number of false-positive results [30] and hence might limit the resources and prevent subjecting women to unnecessary treatments (see Fig. 3). This combination of VIA or VILI and HPV testing has the potential to offer a better benefit-risk balance when compared to other available screening methods currently being used for HIV-seropositive women. However, for developing countries to implement such change, resources, guidelines and policies (which are context-specific) will need to be made available in line with emerging scientific evidence. In addition, the safety interpretation of results of HPV tests requires trained professional to limit overestimation of precancerous lesions in HIV-seropositive women, which may result in unnecessarily subjecting women to treatment that they do not need as well as waste the limited resources. Therefore, this requires training of healthcare workers when implementing HPV testing.

With improved knowledge and understanding of cervical cancer and HPV, several studies [52-57] have indicated the immunogenicity and safety of the currently used HPV vaccine amongst young and middle-aged HIV-seropositive women. There is scanty data on implementation of the HPV vaccination, its efficacy and uptake amongst HIV-positive women as the available evidence focuses on the safety and immunogenicity [5258]. However, guidelines by the Centers for Disease Control and Prevention and HIV Medicine Association of Infectious Diseases Society of America recommend HPV vaccination amongst young HIV-seropositive women aged 13 to 26 years [59]. Most developing countries have embarked on mass HPV vaccination of young girls, and opportunities for effective and sustainable implementation of the vaccine amongst HIV-positive young girls exist and should be utilised. As the implementation of the mass HPV vaccination intensifies in developing countries, opportunities to increase the age of recipients to include middle-aged HIV-seropositive women should be explored and initiated as suggested in Fig. 3.

\section{Analytic frameworks for decision-making in screening} For developing countries, questions on how to implement and sustain cervical cancer screening in light of limited resources (human and financial), inadequate infrastructure and lack of screening programmes still exist. The questions continue to have an impact on decision-making towards screening and even prioritisation of HIV-seropositive women. In as much as this review has generated synthesised evidence on cervical cancer screening of HIV-seropositive women, utilisation and implementation of some of this evidence will be context-specific. A number of analytic frameworks for decision-making in cervical cancer screening exist [6063], and these frameworks may help developing countries in identifying cost-effective strategies towards screening of HIV-seropositive women. These analytic frameworks can assist countries to make decisions after considering the provided evidence, epidemiological 


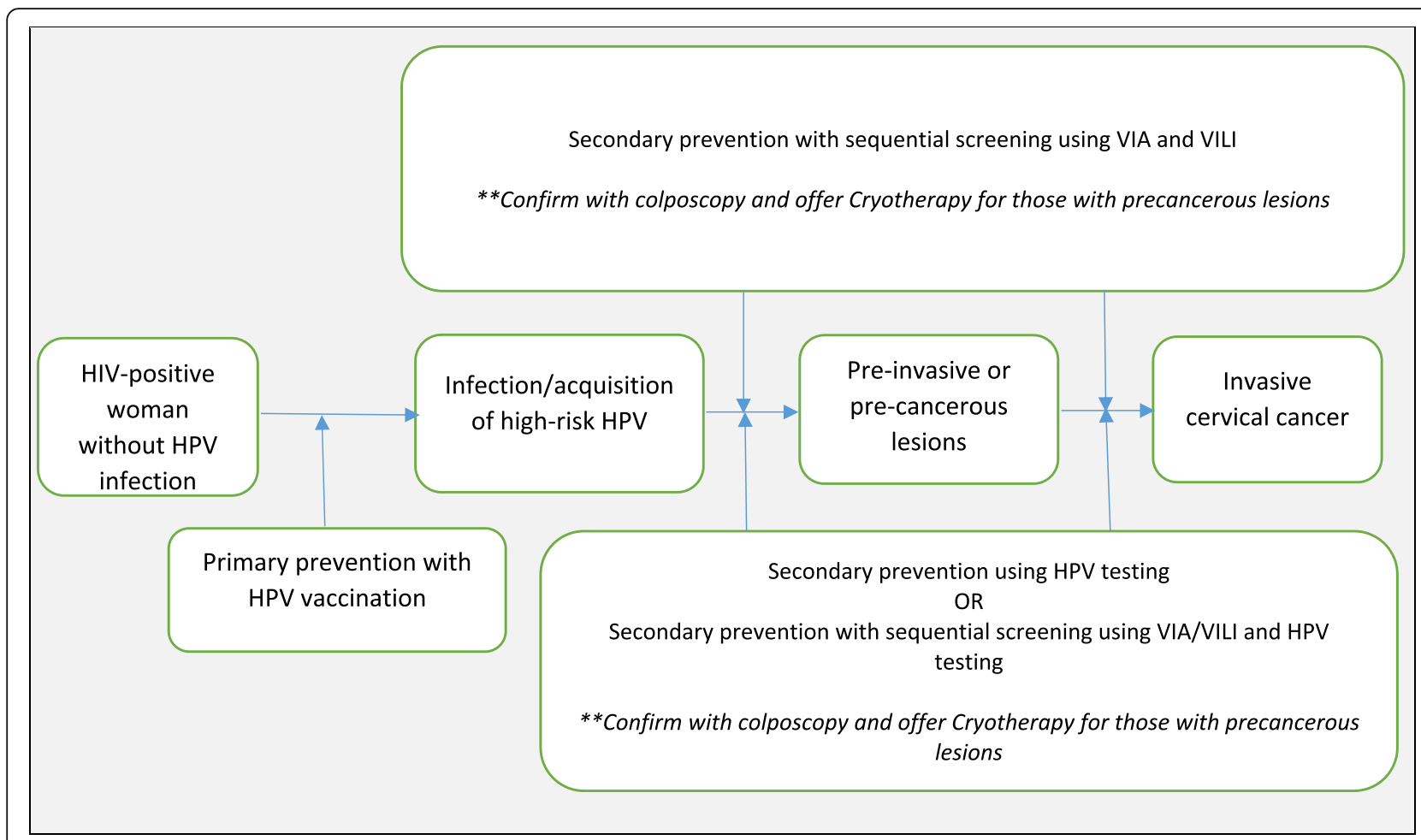

Fig. 3 Proposed opportunities for prevention of cervical cancer in HIV-seropositive women. ${ }^{*}$ Treatment with cryotherapy or LEEP should be offered after the results are verified by qualified personnel to limit subjecting these patients to unnecessary treatments. HPV, human papillomavirus; VIA, visual inspection with acetic acid; VILI, visual inspection with Lugol's iodine; LEEP, loop electrosurgical excision procedure

factors, political and economic factors and issues around equity and costumers' preferences [64]. Such a transparent and systematic way of making decisions has been shown to have a positive impact on screening $[61,63]$.

\section{Limitations}

The overall quality of evidence of the included studies, which was 'moderate', made it difficult to draw emphatic conclusions on which screening method/tool is effective on HIV-seropositive women and which one is suitable for low-income countries. The validity of the results was decreased by the risk of bias associated with the study designs, completeness of data and lack of explanations on the statistical analyses conducted. Lastly, by limiting the searching to studies reported in English, this review might have missed some relevant studies published in other languages.

\section{Conclusion}

HIV-seropositive women are a high-risk group for developing cancer [5, 7], and identifying the ideal cervical cancer screening method for them will go a long way in reducing premature mortality amongst them. Findings of this review indicate a need for further research, mostly randomised controlled trials, that allows adequate follow-up of screened HIV-seropositive women and provide evidence on which screening method is best to use, taking into account age, one visit vs. return visit schemes, primary screening then triage, opportunistic vs. organised screening, CD4+ counts, antiretroviral therapy and quality of life.

Sequential screening using HPV test and VIA or VILI has the potential to offer a better catch of at-risk HIV-positive women [30] when compared to the other available screening methods, and this can be a solid foundation that developing countries can start to formulate their cervical cancer screening guidelines for HIV-seropositive women. However, as indicated before, there is a need for further research that will provide evidence on the best way of using this combination since it was reported that such sequential screening did not improve sensitivity or specificity [27].

Secondly, with the introduction of mass HPV vaccination amongst school-going young girls, there exist potential opportunities to offer the vaccine to middle-aged HIV-seropositive women in developing countries within well-established HIV programmes. With HPV vaccine offering more than 12 months protection in HIV-seropositive women [15], this might be a cost-effective and simple method to offer cervical cancer prevention amongst these women. In addition, HPV vaccination will offer a solution to the lack of adequate 
suitable infrastructure and trained professionals that has hampered Pap smear screening in developing countries.

Developing countries should strive to offer both opportunistic and organised coordinated screening programmes in the form of provider initiated. Furthermore, there is a need to expand the integration of provider-initiated cervical cancer screening services in already existing HIV services so as to enable early detection and treatment and offer a 'one-stop' shop. Developing countries can think of individualising cervical cancer screening depending on their available resources and context to cater for the benefit/risk of different screening methods and the general health status of the HIV-seropositive women. This is in light with the proposed see-see and treat method where the potential of high false positives and over treating can be reduced significantly [38].

\section{Implications of the review's results in evidence-based health care}

Based on the proposed opportunities for prevention of cervical cancer in HIV-seropositive women (see Fig. 3), a number of key messages around the reliability of the found evidence are beginning to emerge.

There is no best available cervical cancer screening method/tool for HIV-seropositive women, and the current presented evidence can be effective in certain contexts but not all. Future research can explore the feasibility, appropriateness, meaningfulness and cost-effectiveness of HPV vaccine; use of the see-see and treat using VIA/VILI, colposcopy and cryotherapy; and sequential screening using VIA/VILI and or HPV testing in HIV-burdened countries. Whatever method is to be used, the invention of a systematic screening approach, which could be helpful, should be investigated and based on cervical cancer analytic frameworks to allow transparent and systematic decision-making [61, 64].

Clients or patients should at least have an option to decide on which screening method they would prefer based on the risk-benefit balance, and this should be guided by professional judgement of healthcare staff.

\section{Additional files}

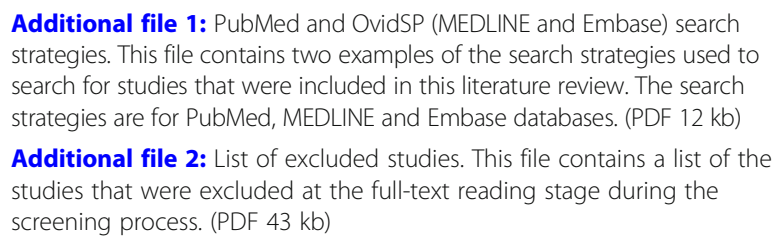

\section{Abbreviations}

CIN2+: Cervical intraepithelial neoplasia grade 2+; CINAHL: Cumulative Index to Nursing and Allied Health Literature; DC: Digital cervicography; EMBASE: Excerpta Medica Database; HC2: Hybrid Capture-2; HIV: Human immunodeficiency virus; HPV DNA/mRNA: Human papillomavirus deoxyribonucleic acid/messenger RNA; HPV: Human papillomavirus; PRISMA: Preferred Reporting Items for Systematic Review and Meta-Analysis; RCT: Randomised controlled trial; VIA: Visual inspection with acetic acid; VILI: Visual inspection with Lugol's iodine

\section{Acknowledgements}

We gratefully acknowledge Rutendo Chinomona-Mapanga for her helpful comments and suggestions on the systematic review.

\section{Funding}

The University of Pretoria (programme code 10260404) funded this review. The funder had no role in the design of the study, interpretation of the data, writing this manuscript or the decision to publish the review.

\section{Availability of data and materials}

The analysed and generated data for this review are included in this publication and its supplementary files.

\section{Authors' contributions}

WM designed the review and registered it with PROSPERO. WM led the execution of the literature searches, data abstraction and analysis. TC, BGB, SF and ES participated in the review process, literature search, data abstraction and synthesis. All the authors revised the manuscript critically and approved the final version of it.

\section{Authors' information}

WM is studying towards a PhD Epidemiology Degree at the School of Health Systems and Public Health, University of Pretoria, and is investigating on cervical cancer in low-income countries. BGB is a professor of Biostatistics at the Department of Epidemiology and Biostatistics at the University of Pretoria. ES is the Director of the South African National Cancer Registry. TC is a professor of Obstetrics and Gynaecology at the College of Health Sciences, University of Zimbabwe. SF is a professor of Biostatistics and Epidemiology at the Faculty of Health Sciences, University of Fort Hare.

\section{Ethics approval and consent to participate}

The Research Ethics Committee, Faculty of Health Science, University of Pretoria, reviewed the study (Ethics Reference Number: 146/2016).

\section{Consent for publication}

Not applicable.

\section{Competing interests}

The authors declare that they have no competing interests.

\section{Publisher's Note}

Springer Nature remains neutral with regard to jurisdictional claims in published maps and institutional affiliations.

\section{Author details}

'School of Health Systems and Public Health, Epidemiology \& Biostatistics, University of Pretoria, 5-10 H.W. Snyman Building, Pretoria, South Africa. ${ }^{2}$ Faculty of Health Sciences, University of Fort Hare, 45 Church Street, Gasson Building, 7th Floor, P.O. Box 1054, East London 5201, South Africa. ${ }^{3}$ Department of Obstetrics and Gynaecology, College of Health Sciences, University of Zimbabwe, Avondale, Harare, Zimbabwe. ${ }^{4}$ Cancer Epidemiology Research Group, National Cancer Registry, National Health Laboratory Service, Johannesburg, South Africa. ${ }^{5}$ Harare, Zimbabwe.

Received: 4 July 2018 Accepted: 5 November 2018

Published online: 17 November 2018

\section{References}

1. World Health Organisation. Human papilloma virus (HPV). Available at http://www.who.int/immunization/topics/hpv/en/ Accessed 23 May 2018.

2. Chirenje ZM. HIV and cancer of the cervix. Best Pract Res Clin Obstet Gynaecol. 2005;19:269-76.

3. Clifford GM, Polesel J, Rickenbach M. Cancer risk in the Swiss HIV Cohort Study: associations with immunodeficiency, smoking, and highly active 
antiretroviral therapy. Journal of the National Cancer Institute. 2005;97(6): 425-32.

4. Moodley JR, Hoffman M, Carrara H, Allan BR, Cooper DD, Rosenberg L, et al. HIV and pre-neoplastic and neoplastic lesions of the cervix in South Africa: a case-control study. BMC Cancer. 2006;6:135.

5. Santesso N, Mustafa RA, Schünemann HJ, Arbyn M, Blumenthal PD, Cain J, Chirenje M, et al. World Health Organization Guidelines for treatment of cervical intraepithelial. Neoplasia 2-3 and screen-and-treat strategies to prevent cervical cancer. Int J Gynaecol Obstet. 2016;132(2):252-8.

6. Sichanh C, Quet F, Chanthavilay P, Diendere J, Latthaphasavang V, Longuet $C$, et al. Knowledge, awareness and attitudes about cervical cancer among women attending or not an HIV treatment center in Lao PDR. BMC Cancer. 2014;14:161.

7. Finocchario-Kessler S, Wexler C, Maloba M, Mabachi N, Ndikum-Moffor F, Bukusi E. Cervical cancer prevention and treatment research in Africa: a systematic review from a public health perspective. BMC Womens Health. 2016;16(29):1-25.

8. Mishra GA, Pimple SA, Shastri SS. An overview of prevention and early detection of cervical cancers. Indian J Med Paediatr Oncol. 2011;32(3):125-32.

9. Fallala MS, Mash R. Cervical cancer screening: safety, acceptability and feasibility of a single-visit approach in Bulawayo, Zimbabwe. Afr J Prm Health Care Fam Med. 2015;7(1):742-9.

10. McFarland DM, Gueldner SM, Mogobe KD. Integrated review of barriers to cervical cancer screening in sub-Saharan Africa. J Nurs Scholarsh. 2016;48(5): 490-8.

11. Chirenje ZM, Rusakaniko S, Kirumbi L, Ngwalle EW, Makuta-Tlebere PP, Kaggwa S, Mpanju-Shumbusho W, Makoae L. Situation analysis for cervical cancer diagnosis and treatment in East, Central and Southern African countries. World Health Organisation. 2001;79(2):127-32.

12. Lim JN, Ojo AA. Barriers to utilisation of cervical cancer screening in subSahara Africa: a systematic review. Eur J Cancer Care (Engl). 2017;26(1). https://doi.org/10.1111/ecc.12444 Epub 07 Feb 2016.

13. Public Health Association of South Africa. Implementation of HPV vaccination in South Africa. 2015.

14. Ghebre RG, Grover S, Xu MJ, Chuang LT, Simonds H. Cervical cancer control in HIV-infected women: past, present and future. Gynecologic Oncology Reports. 2017;21:101-8.

15. Kojic EM, Rana Al, Cu-Uvin S. Human papillomavirus vaccination in HIVinfected women: need for increased coverage. Expert review of vaccines. 2016;15(1):105-17. https://doi.org/10.1586/14760584.2016.1110025.

16. Mapanga W, Elhakeem A, Feresu SA, Maseko F, Chipato T. Prevention of cervical cancer in HIV-seropositive women from developing countries: a systematic review protocol. Syst Rev. 2017;6(1):91 10.1186/s13643-017-0484-9.

17. Moher D, Liberati A, Tetzlaff J, Altman DG, The PRISMA Group. Preferred Reporting Items for Systematic Reviews and Meta-Analyses: the PRISMA Statement. PLoS Med. 2009;6(7):e1000097 https://doi.org/10.1371/journal. pmed. 1000097.

18. Wells GA, Shea B, O'Connell D, Peterson J, Welch V, Losos M, Tugwell P. The Newcastle-Ottawa Quality Assessment Scale Available at http://www.ohri.ca/ programs/clinical_epidemiology/oxford.asp [Accessed 11 Oct 2016].

19. NIH Study Quality Assessment Tools. Available at https://www.nhlbi.nih.gov/ health-topics/study-quality-assessment-tools [Accessed 2 Oct 2018].

20. Huchko MJ, Sneden J, Zakaras JM, Smith-McCune K, Sawaya G, Maloba M,

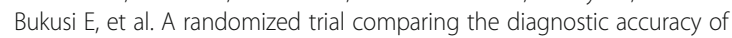
visual inspection with acetic acid to visual inspection with Lugol's iodine for cervical cancer screening in HIV-infected women. Plos One. 2015. https:// doi.org/10.1371/journal.pone.0118568.

21. Kuhn L, Wang C, Tsai WY, Wright TC, Denny L. Efficacy of human papillomavirus-based screen-and-treat for cervical cancer prevention among HIV-infected women. AIDS. 2010;24(16):2553-61.

22. Huchko MJ, Sneden J, Leslie HH, Abdulrahim N, Maloba M, Bukusi E, et al. A comparison of two visual inspection methods for cervical cancer screening among HIV-infected women in Kenya. Bull World Health Organ. 2014;92(3):195-203.

23. Obiri-Yeboah D, Adu-Sarkodie Y, Djigma F, Akakpo K, Aniakwa-Bonsu E, Amoako-Sakyi D, et al. Options in human papillomavirus (HPV) detection for cervical cancer screening: comparison between full genotyping and a rapid qualitative HPV-DNA assay in Ghana. Gynecol Oncol Res Pract. 2017:4:5.

24. Obiri-Yeboah D, Adu-Sarkodie Y, Djigma F, Hayfron-Benjamin A, Abdul L, Simpore J, et al. Self-collected vaginal sampling for the detection of genital human papillomavirus (HPV) using careHPV among Ghanaian women. BMC Womens Health. 2017;17(1):86.
25. Bansil P, Lim J, Byamugisha J, Kumakech E, Nakisige C, Jeronimo JA. Performance of cervical cancer screening techniques in HIV-infected women in Uganda. J Low Genit Tract Dis. 2015;19(3):215-9.

26. Cholli P, Bradford L, Manga S, Nulah K, Kiyang E, Manjuh F, et al. Screening for cervical cancer among HIV-positive and HIV-negative women in Cameroon using simultaneous co-testing with careHPV DNA testing and visual inspection enhanced by digital cervicography: findings of initial screening and one-year follow-up. Gynecol Oncol. 2018;148(1):118-25.

27. Chung MH, McKenzie K, De Vuyst $\mathrm{H}$, et al. Comparing Papanicolau smear, visual inspection with acetic acid and human papillomavirus cervical cance screening methods among HIV-positive women by immune status and antiretroviral therapy. AIDS. 2013;27(18):2909-19.

28. Dartell MA, Rasch V, Ifner $T$, et al. Performance of visual inspection with acetic acid and human papillomavirus testing for detection of high-grade cervical lesions in HIV positive and HIV negative Tanzanian women. Int J Cancer. 2014;135(4):896-904.

29. Firnhaber C, Goeieman B, Faesen M, Levin S, Williams S, Rameotshela S, et al. Prospective one year follow up of HIV infected women screened for cervical cancer using visual inspection with acetic acid, cytology and human papillomavirus testing in Johannesburg South Africa. PLoS One. 2016;11(1):e0144905.

30. Joshi S, Sankaranarayanan R, Muwonge R, Kulkarni V, Somanathan T, Divate U. Screening of cervical neoplasia in HIV-infected women in India. AIDS. 2013:27(4):607-15

31. Lim K, Davidson A, Harwell J, Thay S, Boardman LA, Feller E, et al. Comparing visual inspection with acetic acid to cytology in detection of precancerous lesions of the cervix in HIV-infected Cambodian women. J Int Assoc Physicians AIDS Care (Chic). 2011;10(5):283-6.

32. Mabeya H, Khozaim K, Liu T, et al. Comparison of conventional cervical cytology versus visual inspection with acetic acid (VIA) among HIV-infected women in western Kenya. J Low Gen Tract Dis. 2012;16(2):92-7.

33. Michelow P, Sherrin A, Rossouw L, Mohaleamolla S, Evans D, Swarts A, et al. Performance of the Cellslide((R)) automated liquid-based cytology system amongst HIV-positive women. Afr J Lab Med. 2016;5(1):278.

34. Sahasrabuddhe W, Bhosale RA, Kavatkar AN, Nagwanshi CA, Joshi SN, Jenkins $C A$, et al. Comparison of visual inspection with acetic acid and cervical cytology to detect high-grade cervical neoplasia among HIVinfected women in India. Int J Cancer. 2012;130(1):234-40.

35. Akinwuntwan L, Adesina OA, Okolo CA, et al. Correlation of cervical cytology and visual inspection with acetic acid in HIV-positive women. J Obstet and Gynaecol. 2008;28(6):638-41.

36. Segondy M, Kelly H, Djima F, et al. Performance of careHPV for detecting highgrade cervical intraepithelial neoplasia among women living with $\mathrm{HIV}-1$ in Burkina Faso and South Africa: HARP study. Br J Cancer. 2016;1 15(4):425-30.

37. Bateman AC, Parham GP, Sahasrabuddhe W, Mwanahamuntu MH, Kapambwe S, Katundu K, et al. Clinical performance of digital cervicography and cytology for cervical cancer screening in HIV-infected women in Lusaka, Zambia. J Acquir Immune Defic Syndr. 2014;67(2):212-5. https://doi.org/10. 1097/QAl.0000000000000270.

38. Mutyaba T, Mirembe F, Sandin S, Weiderpass E. Evaluation of 'see-see and treat' strategy and role of HIV on cervical cancer prevention in Uganda. Reprod Health. 2010;7:4.

39. Ngou J, Gilham C, Omar T, Goumbri-Lompo O, Doutre S, Michelow P, et al. Comparison of analytical and clinical performances of the digene HC2 HPV DNA assay and the INNO-LiPA HPV genotyping assay for detecting high-risk HPV infection and cervical neoplasia among HIV-positive African women. J Acquir Immune Defic Syndr. 2015;68(2):162-8.

40. Ngou J, Magooa MP, Gilham C, Djigma F, Didelot MN, Kelly H, et al. Comparison of careHPV and hybrid capture 2 assays for detection of highrisk human papillomavirus DNA in cervical samples from HIV-1-infected African women. J Clin Microbiol. 2013;51(12):4240-2.

41. Firnhaber C, Mayisela N, Mao L, et al. Validation of cervical cancer screening methods in HIV positive women from Johannesburg South Africa. PLoS One. 2013;8(1):e53494.

42. Wu TJ, Smith-McCune K, Reuschenbach M, von Knebel DM, Maloba M, Huchko MJ. Performance of p16INK4a ELISA as a primary cervical cancer screening test among a large cohort of HIV-infected women in western Kenya: a 2-year cross-sectional study. BMJ Open. 2016;6(9):e012547.

43. Chibwesha CJ, Frett B, Katundu K, et al. Clinical performance validation of 4 point-of-care cervical cancer screening tests in HIV-infected women in Zambia. J Low Gen Tract Dis. 2016;20(3):218-23. 
44. Adamson PC, Huchko MJ, Moss AM, Kinkel HF, Medina-Marino A. Acceptability and accuracy of cervical cancer screening using a selfcollected tampon for HPV messenger-RNA testing among HIV-infected women in South Africa. PLoS One. 2015;10(9):e0137299.

45. Viviano M, DeBeaudrap P, Tebeu PM, Fouogue JT, Vassilakos P, Petignat P. A review of screening strategies for cervical cancer in human immunodeficiency virus-positive women in sub-Saharan Africa. Int J Women's Health. 2017;9:69-79.

46. Shiferaw N, Salvador-Davila G, Kassahun K, et al. The single-visit approach as a cervical cancer prevention strategy among women with HIV in Ethiopia. Successes and lessons learned. Glob Health Sci Pract. 2016;4(1):87-98.

47. Crosbie EJ, Einstein MH, Franceschi S, Kitchener HC. Human papillomavirus and cervical cancer. Lancet. 2013;382(9895):889-99.

48. Schiffman M, Solomon D. Cervical-cancer screening with human papillomavirus and cytologic cotesting. N Engl J Med. 2013:369:2324-31.

49. Alizon S, Murall CL, Bravo IG. Why human papillomavirus acute infections matter. Viruses. 2017;9(293). https://doi.org/10.3390/v9100293.

50. Castle PE, Rodriguez AC, Burk RD, Herrero R, Wacholder S, Hildesheim A, et al. Long-term persistence of prevalently detected human papillomavirus infections in the absence of detectable cervical precancer and cancer. J Infect Dis. 2011:203(6):814-22

51. Gravitt PE, Rositch AF. HPV self-testing and cervical cancer screening coverage. Lancet Oncol. 2014;15(2):128-9.

52. Palefsky J, Poongulali S, Lensing SY, Lee JY, Da Costa M, Jeeva A, Iqbal S, Kumarsami N. AMC 054: safety and immunogenicity of the quadrivalent HPV vaccine in Indian HIV-infected women. Boston: Conference on Retroviruses and Opportunistic Infections; 2014. p. 2014.

53. Kojic EM, Kang M, Cespedes MS, Umbleja T, Godfrey C, Allen RT, Firnhaber C, Grinsztejn B, Palefsky JM, Webster-Cyriaque JY, et al. Immunogenicity and safety of the quadrivalent human papillomavirus vaccine in HIV-1-infected women. Clin Infect Dis. 2014;59(1):127-35.

54. Denny L, Hendricks B, Gordon C, Thomas F, Hezareh M, Dobbelaere K, Durand C, Herve C, Descamps D. Safety and immunogenicity of the HPV-16/18 AS04adjuvanted vaccine in HIV-positive women in South Africa: a partially-blind randomised placebo-controlled study. Vaccine. 2013;31(48):5745-53.

55. Kahn JA, Xu J, Kapogiannis BG, Rudy B, Gonin R, Liu N, Wilson CM, Worrell C, Squires KE. Immunogenicity and safety of the human papillomavirus 6, 11, 16, 18 vaccine in HIV-infected young women. Clin Infect Dis. 2013;57(5):735-44.

56. Toft L, Tolstrup M, Muller M, Sehr P, Bonde J, Storgaard M, Ostergaard L, Sogaard OS. Comparison of the immunogenicity of Cervarix(R) and Gardasil(R) human papillomavirus vaccines for oncogenic non-vaccine serotypes HPV-31, HPV-33, and HPV-45 in HIV-infected adults. Hum Vaccin Immunother. 2014;10(5):1147-54.

57. Giacomet V, Penagini F, Trabattoni D, Vigano A, Rainone V, Bernazzani G, Bonardi CM, Clerici M, Bedogni G, Zuccotti GV. Safety and immunogenicity of a quadrivalent human papillomavirus vaccine in HIV-infected and HIVnegative adolescents and young adults. Vaccine. 2014;32(43):5657-61.

58. Kojic EM, Rana Al, Cu-Uvin S. Human papillomavirus in HIV-infected women: need for increased coverage. Expert Rev Vaccines. 2016;15(1):105-17.

59. Masur H, Brooks JT, Benson CA, Holmes KK, Pau AK, Kaplan JE. Prevention and treatment of opportunistic infections in HIV-infected adults and adolescents: updated guidelines from the Centers for Disease Control and Prevention National Institutes of Health, and HIV Medicine Association of the Infectious Diseases Society of America. Clin Infect Dis. 2014;58(9):1308-11.

60. Briss P, Rimer B, Reilley B, Coates RC, Lee NC, Mullen P, et al. Promoting informed decisions about cancer screening in communities and healthcare systems. Am J Prev Med. 2004;26(1):67-80.

61. Miot J, Wagner M, Khoury H, Rindress D, Goetghebeur M. Field testing of a multicriteria decision analysis (MCDA) framework for coverage of a screening test for cervical cancer in South Africa. Cost Effectiveness and Resource Allocation. 2012;10:2.

62. Pedersen K, Sorbye SW, Burger EA, Lonnberg S, Kristiansen IS. Using decision-analytic modeling to isolate interventions that are feasible, efficient and optimal: an application from the Norwegian cervical cancer-screening program. Value Health. 2015;18:1088-97.

63. Claxton K, Sculpher M, Drummond M. A rational framework for decision making by the National Institute for Clinical Excellence (NICE). Lancet. 2002; 360:711-5

64. Goldie SJ, Goldhaber-Fiebert JD, Garnett GP. Chapter 18: public health policy for cervical cancer prevention: the role of decision science, economic evaluation, and mathematical modelling. Vaccine. 2006;24S3:S3/155-63.

Ready to submit your research? Choose BMC and benefit from:

- fast, convenient online submission

- thorough peer review by experienced researchers in your field

- rapid publication on acceptance

- support for research data, including large and complex data types

- gold Open Access which fosters wider collaboration and increased citations

- maximum visibility for your research: over $100 \mathrm{M}$ website views per year

At BMC, research is always in progress.

Learn more biomedcentral.com/submissions 